Sādhanā Vol. 38, Part 6, December 2013, pp. 1083-1126. (C) Indian Academy of Sciences

\title{
Two-phase flow boiling in small channels: A brief review
}

\author{
MADHAVI V SARDESHPANDE* and VIVEK V RANADE \\ Industrial Flow Modelling Group, Chemical Engineering and Process Development \\ Division, National Chemical Laboratory, Pune 411 008, India \\ e-mail: mv.sardeshpande@ncl.res.in
}

MS received 11 July 2012; revised 17 January 2013; accepted 31 January 2013

\begin{abstract}
Boiling flows are encountered in a wide range of industrial applications such as boilers, core and steam generators in nuclear reactors, petroleum transportation, electronic cooling and various types of chemical reactors. Many of these applications involve boiling flows in conventional channels (channel size $\geq 3 \mathrm{~mm}$ ). The key design issues in two phase flow boiling are variation in flow regimes, occurrence of dry out condition, flow instabilities, and understanding of heat transfer coefficient and vapor quality. This paper briefly reviews published experimental and modeling work in these areas. An attempt is made to provide a perspective and to present available information on boiling in small channels in terms of channel size, flow regimes, heat transfer correlations, pressure drop, critical heat flux and film thickness. An attempt is also made to identify strengths and weaknesses of published approaches and computational models of boiling in small channels. The presented discussion and results will provide an update on the state-of-the-art and will be useful to identify and plan further research in this important area.
\end{abstract}

Keywords. Boiling; two-phase flow; small channel; dry-out; heat transfer; instabilities.

\section{Introduction}

Boiling in small channels is a topic of current interest with its application to steam tubes in boilers, compact evaporators, compact heat exchangers, tubes in refrigerant industries, and microelectronics devices with heat pipes etc. Practical development of these devices is creating a need of better understanding of transport phenomenon in small channels. In each application it is observed that a phase-change heat transfer is playing a vital role. Phase change process particularly flow boiling are important in the micro and macro scale devices but relatively little work has been done in this area. Systems employing small channels offer many advantages such as compact physical size, small thermal resistances between the device and coolant, high heat transfer coefficients, reduced inventory requirements, low capital cost etc. Boiling flows inside small channels provide a very effective way of heat transfer; generally more than single phase flow.

*For correspondence 
The rapid development of small, mini and micro fluidic devices is motivating the demand for comprehensive understanding of transport mechanisms involved in boiling through such small channels.

Flow boiling has been studied extensively in the last few decades. However, flow boiling heat transfer and two-phase flow transport phenomena in small, mini and micro hydraulic diameter channels are quite different from conventional large channels. Some of the industrial applications falling over a channel size ranging from $0.33 \mathrm{~mm}$ to $20 \mathrm{~mm}$ are shown in figure $1 \mathrm{a}-\mathrm{b}$.

Basically, two-phase flow boiling heat transfer in tubes or channels can be characterized by either nucleate or convective boiling component or both. All three possibilities have been

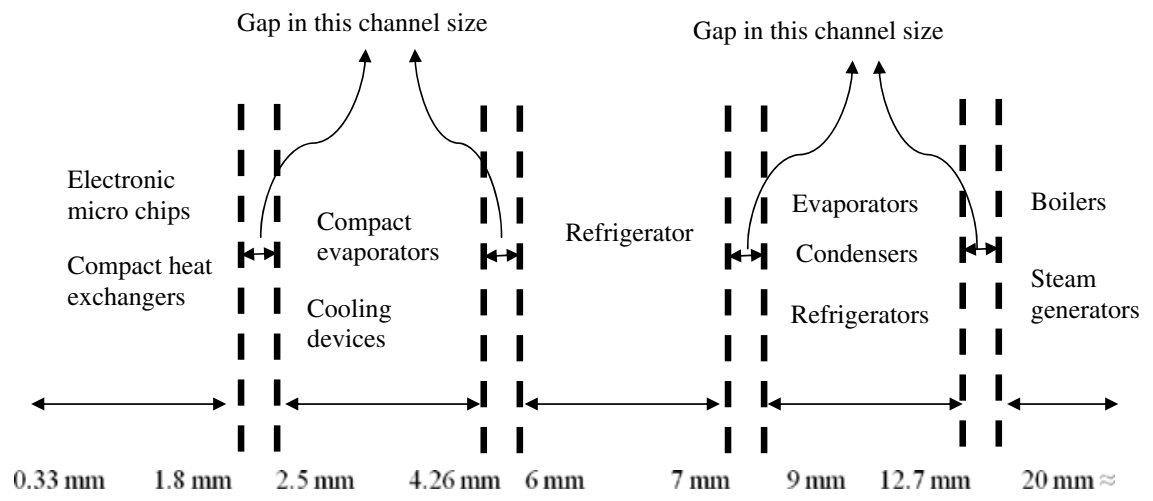

(a)
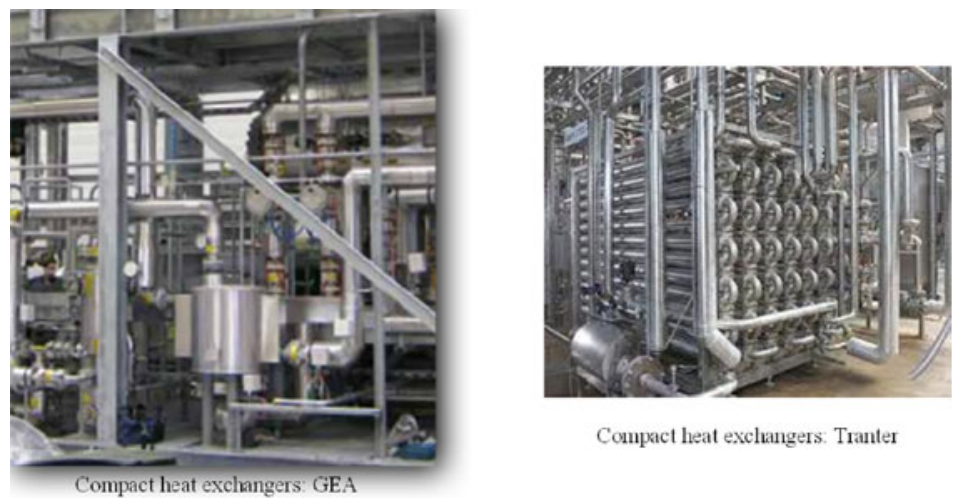

Compact heat exchangers: Tranter

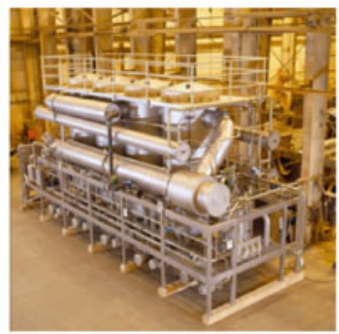

(b)

Compact evaporator: GEA

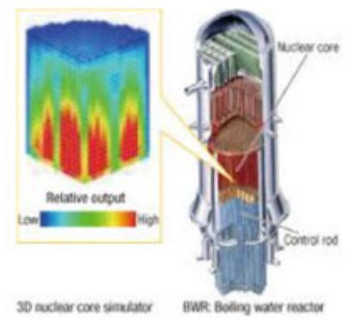

Steam generator: Hitachi

Figure 1. (a) Schematic representation of gaps identified in literature on channel size. (b) Pictorial view of industrial equipments where two-phase flow is shown. 
reported based on experiments under different operating parameters. Over the past decades, a lot of work has been done to understand the fundamental aspects of two-phase flow and flow boiling of mixtures in various channel sizes. These include mainly experiments on flow boiling and development of heat transfer correlations for mixtures. A widely used approach is to assume that heat is transferred by a combination of nucleate boiling and convective boiling. In nucleate boiling, thin liquid films are created cyclically under small bubbles growing in contact with the wall at individual nucleation sites and the wall superheat. The heat transfer coefficient increases nonlinearly with increasing heat flux but it is insensitive to the flow rate through the channel. In convective boiling, heat is transferred from the wall through the laminar sub-layer to the turbulent flow of the mixture of liquid and bubbles that have detached from the wall and coalesced and results into different flow regimes as shown in figure 2 .

As may be seen from figure 2, a sub-cooled liquid enters the tube (heated uniformly along its length at a relatively low heat flux) from the bottom and then completely evaporates over the length of the tube. While the liquid is being heated up to its saturation temperature, the wall temperature initially is below that necessary for nucleation (zone A). Thus, the heat transfer process in zone A is sub-cooled, single-phase heat transfer to the liquid, which may be laminar or turbulent. Then the wall temperature rises above the saturation temperature and boiling
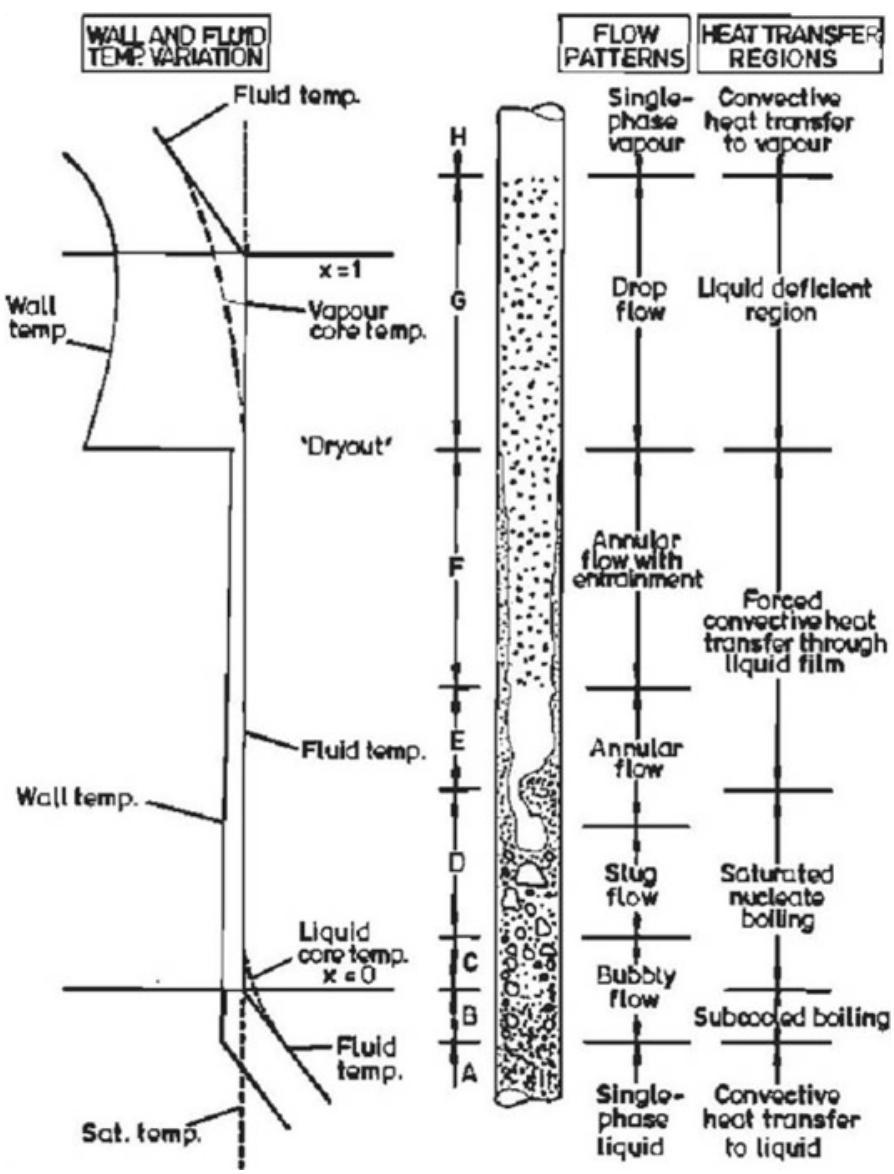

Figure 2. Heat transfer regions in convective boiling in a vertical tube from Collier \& Thome (1994). 
nucleation takes place in the superheated thermal boundary layer on the tube wall, such that subcooled flow boiling occurs in zone B with the vapour bubbles condensing as they drift into the sub-cooled core. The liquid then reaches its saturation temperature and saturated boiling in the form of bubbly flow begins in zone C. Saturated boiling continues through the slug flow regime (zone D), the annular flow regime (zone E) and then the annular flow regime with liquid entrainment in the vapour core (zone F). At the end of zone F, the annular film is either dried out or sheared from the wall by the vapour, a point that is referred to as the onset of 'dry-out' or simply dry-out. Above this point, mist flow in the form of entrained droplets occurs with a large increase in wall temperature of an imposed wall heat flux (zone G). The temperature of the continuous vapour phase in zone $\mathrm{G}$ tends to rise above the saturation temperature where the vapour quality is 1 .

As can be seen from figure 2, two-phase flow boiling occurring inside a tube leads to be unstable because of random movements of liquid and vapour. Two-phase flow instabilities induced during flow boiling in thermal systems are undesirable as they can result in mechanical vibrations and system control problems, affect normal operation, restrict operating parameters and influence system safety. The proper characterization of these instabilities and the condition for their occurrence would facilitate optimal and safe operation of the involved systems. The safe operating regime of a two-phase flow can be determined by the instability values of system parameters such as flow rate, pressure, wall temperatures, and exit mixture quality.

As mentioned above, design of small channel depends on heat transfer coefficient, flow regimes, heat and mass fluxes and vapour quality. Despite significant research efforts, it is observed that traditional heat transfer coefficient correlations for saturated boiling with liquidturbulent and gas-turbulent flows may not be suitable to predict heat transfer coefficients in small channels due to possibility of laminar flow. Although many analytical and experimental studies related to flow boiling heat transfer in small channels have been performed during the past decades, adequate systematic and accurate data bases are still unavailable and reliable heat transfer coefficient correlation applicable to a wide range of conditions in small-channels is often difficult to identify.

In the present review, we focus specifically on boiling in small channels. Existing experimental and modelling studies on flow boiling in small channels are critically reviewed. Summary of published results are presented in the form of easy to read and easy to assimilate tables. We try to identify key conclusions as well as the key gaps from already published studies and suggest some general issues to keep in mind in any further research on boiling in small channels.

\section{Two-phase flow boiling}

We focus on "classification" of channels based on their sizes due to a general lack of agreement in the definition of such classification as can be seen in existing literature. The need for such a classification is important for comparative studies of two-phase flow boiling in a given category of "channel" under various experimental conditions.

In the following sub-sections, we discuss briefly the role of channel size and several other parameters necessary in the understanding of two-phase flow.

\subsection{Channel size}

As mentioned above, boiling inside small passages provides a very effective way of fluid movement, as well as relatively large heat dissipation capabilities for specialized applications. 


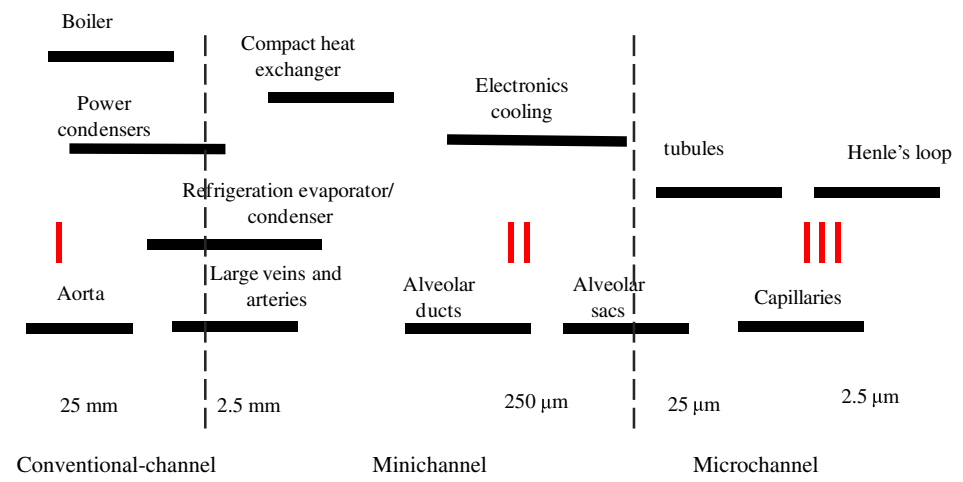

Figure 3. Ranges of channel diameters employed in various applications, Kandlikar \& Steinke (2003).

Therefore it is prudent to distinguish between small, mini, and micro channels based on engineering practice and application areas employing these channels. Kandlikar \& Steinke (2003) showed ranges of channel dimensions employed in various systems (figure 3) and also few applications as per channel dimensions (table 1).

Table 1. Applications of boiling in small channels.

\begin{tabular}{|c|c|c|c|}
\hline Author and year & Channel size & Fluid & Applications \\
\hline Tran et al (1996) & $\begin{array}{l}\text { Circular }-2.46 \mathrm{~mm} \\
\text { Rectangular }-1.76 \times \\
4.06 \mathrm{~mm}\end{array}$ & $\mathrm{R} 12$ & Compact evaporators \\
\hline Peles \& Haber (2000) & Circular $-300 \mu \mathrm{m}$ & Water & Micro heat pipes \\
\hline Lee \& Lee (2001) & Rectangular $-0.4 \times 2 \mathrm{~mm}$ & R113 & Compact heat exchangers \\
\hline Lin et al (2001) & $\begin{array}{l}\text { Circular }-1.1,1.8,2.8,3.6 \\
\text { Square }-2 \times 2 \mathrm{~mm}\end{array}$ & $\mathrm{R} 141 \mathrm{~b}$ & $\begin{array}{l}\text { Compact evaporators } \\
\text { and condensers }\end{array}$ \\
\hline Zhang et al (2004) & Circular -0.78 to $6 \mathrm{~mm}$ & $\begin{array}{l}\text { Water and R11, } \\
\text { R12 and R113 }\end{array}$ & $\begin{array}{l}\text { Compact heat exchangers, } \\
\text { cooling of electronic chips }\end{array}$ \\
\hline Huo et al (2004) & Circular -4.26 and $2 \mathrm{~mm}$ & $\mathrm{R} 134 \mathrm{a}$ & $\begin{array}{l}\text { Micro devices, compact heat } \\
\text { exchangers and devices for } \\
\text { cooling electronic equipment }\end{array}$ \\
\hline $\begin{array}{l}\text { Kandlikar \& } \\
\text { Balasubramanian } \\
(2004)\end{array}$ & $\begin{array}{l}\text { Circular - 2.92, 1.1, } \\
1.8,0.51 \mathrm{~mm}\end{array}$ & $\mathrm{R} 113, \mathrm{R} 141 \mathrm{~b}$ & $\begin{array}{l}\text { Electronics cooling } \\
\text { and fuel cells }\end{array}$ \\
\hline $\begin{array}{l}\text { Bruno \& Bontemps } \\
\text { (2005) }\end{array}$ & $\begin{array}{l}11 \text { parallel rectangular } \\
\text { channels }-3.28 \times 1.47 \mathrm{~mm}\end{array}$ & $\mathrm{R} 134 \mathrm{a}$ & $\begin{array}{l}\text { Compact heat exchangers } \\
\text { in air conditioning systems }\end{array}$ \\
\hline $\begin{array}{l}\text { Balasubramanian } \\
\text { \& Kandlikar } \\
\text { (2005) }\end{array}$ & $\begin{array}{l}\text { Six parallel } \\
\quad \text { channels }-1054 \times 197 \mu \mathrm{m}^{2}\end{array}$ & Water & $\begin{array}{l}\text { Effect of microgravity used } \\
\text { in space application }\end{array}$ \\
\hline Zhang et al (2006) & Circular -0.33 to $6.22 \mathrm{~mm}$ & Water & $\begin{array}{l}\text { Compact heat exchangers, } \\
\text { electronic chips, } \\
\text { nuclear fusion reactors }\end{array}$ \\
\hline Shiferaw et al (2007) & Circular -2.01 and $4.26 \mathrm{~mm}$ & $\mathrm{R} 134$ & Compact evaporators \\
\hline Shiferaw et al (2009) & Circular - $1.1 \mathrm{~mm}$ & $\mathrm{R} 134 \mathrm{a}$ & Compact evaporators \\
\hline Koichi et al (2004) & $3-6 \mathrm{~mm}$ vertical tube & $\begin{array}{l}\text { Sub cooled } \\
\text { water }\end{array}$ & Nuclear reactors \\
\hline
\end{tabular}


However there is no universal agreement on the threshold channel size that distinguishes small and conventional channels. Shah (1986) defined heat exchanger of a hydraulic diameter $<6 \mathrm{~mm}$ as 'compact'. Mehendale et al (2000) considered the hydraulic diameter range of 1-6 mm for describing compact heat exchangers.

Thus according to both Shah (1986) and Mehendale et al (2000), the threshold hydraulic diameter distinguishing between small and conventional sizes is $6 \mathrm{~mm}$.

Based on engineering practice and application areas such as refrigeration industry, compact evaporators employed in automotive, aerospace, air separation and cryogenic industries, Kandlikar $(2001,2002)$ defined the tube diameter ranges from 3 to $25 \mathrm{~mm}$. It was observed that for all the data was given by Kandlikar $(2001,2002)$ was in the turbulent region considering all flow in the liquid phase. As the tube diameter becomes smaller, liquid flow Reynolds number falls in the laminar region.

According to Kandlikar (2001, 2002) and Kandlikar \& Grande (2003), the channel size defining the boundary between small and conventional channel is $3 \mathrm{~mm}$.

Similarly, various other studies quote threshold diameters for distinguishing small channels from conventional ones. However their values depend on the specific experimental conditions (see table 2).

\subsection{Dimensionless numbers}

Many researchers think the criterion ought to be based on the combination of channel size and fluid thermo-hydraulic properties rather than only on channel dimension. Apart from channels size there are several important dimensionless numbers which are used to represent the feature of fluid flow in small channels (see table 3). According to these dimensionless numbers, the distinction between small diameter and normal size channels may be classified as well. In the study of small channels, it is observed that the various hydrodynamic forces, e.g., inertia, viscosity, buoyancy and surface tension, all play an important role concerning the motion of the liquid and vapor flowing in the channel. These forces are taken into account for various non-dimensional groups. Non-dimensional groups are useful in arriving at key basic relations among system variables that are valid for different fluids even under different operating conditions. Some of these groups have been derived empirically, often on the basis of experimental data. Fundamental considerations of the governing forces and their mutual interactions lead to non-dimensional groups that provide important insight into the physical phenomenon.

Triplett et al (1999) defined the scales in flow channels in terms of the Laplace constant $L$ defined as

$$
L=\sqrt{\frac{\sigma}{g\left(\rho_{l}-\rho_{v}\right)}} .
$$

Here $\sigma$ is surface tension, $g$ is gravitational acceleration, and $\rho_{l}$ and $\rho_{v}$ are liquid and vapour densities respectively.

Kew \& Cornwell (1997) proposed Confinement number, Co for small diameter channels:

$$
\mathrm{Co}=\frac{1}{D_{h}} \sqrt{\frac{4 \sigma}{g\left(\rho_{l}-\rho_{v}\right)}} .
$$

They reported that two-phase flow exhibits different flow and heat transfer characteristics when the confinement number, Co is greater than 0.5. For instance, isolated bubbles prevail when $\mathrm{Co}>0.5$ and form a typical flow regime in small tubes, i.e., confined bubble flow. 
Table 2. Threshold hydraulic channel diameters serving as distinction between small and conventional channels.

\begin{tabular}{|c|c|c|}
\hline Author and year & Threshold size, $\mathrm{mm}$ & Remarks \\
\hline Shah (1986) & 6 & $\begin{array}{l}\text { Hydraulic diameter based on definition of compact heat } \\
\text { exchanger as the one offering surface area to volume } \\
\text { ratio higher than } 700 \mathrm{~m}^{2} / \mathrm{m}^{3}\end{array}$ \\
\hline Mehendale et al (2000) & 6 & $\begin{array}{l}\text { Based on experimental work on R134a in a heat } \\
\text { exchanger consisting of an inlet manifold, } 52 \text { parallel } \\
\text { channels, and an exit manifold }\end{array}$ \\
\hline Kandlikar $(2001,2002)$ & 3 & $\begin{array}{l}\text { Based on the mean free path of molecules in the } \\
\text { single-phase flow, surface tension effects, and flow } \\
\text { patterns in the two-phase flow applications. } \\
3-25 \mathrm{~mm} \text { range studied for turbulent flow }\end{array}$ \\
\hline Wongwises et al (2000) & 7.5 & $\begin{array}{l}\text { Based on studies in evaporative heat transfer involving } \\
\text { HFC 132a in horizontal tubes }\end{array}$ \\
\hline Cheng \& Mewes (2006) & $\begin{array}{c}3 \text { to } 15.8 \\
\text { for water } \\
1 \text { to } 6.8 \text { for } \\
\text { R134a } 6 \text { for } \\
\text { mixture fluids }\end{array}$ & $\begin{array}{l}\text { Studied single component fluid as well as mixtures } \\
\text { over a range of reduced pressures. Threshold } \\
\text { diameters found decreasing as reduced pressure } \\
\text { approached unity }\end{array}$ \\
\hline
\end{tabular}

Similarly, Brauner \& Moalem-Maron (1992) used the Eotvos number Eo for identifying the criterion to distinguish channel sizes. They stated that when

$$
\mathrm{Eo}=\frac{(2 \pi)^{2} \sigma}{\left(\rho_{l}-\rho_{v}\right) D_{h}^{2} g}>1
$$

Table 3. Dimensionless numbers in two-phase boiling.

\begin{tabular}{|c|c|c|}
\hline Dimensionless parameter & Formula & Physical significance \\
\hline Bo (boiling number) & $q /\left(m \times h_{f g}\right)$ & $\begin{array}{l}\text { Ratio of heat exchanged with the surroundings } \\
\text { to the heat that would be liberated by the } \\
\text { complete vapourization of the input liquid }\end{array}$ \\
\hline $\begin{array}{l}\text { Co (confinement } \\
\text { number) }\end{array}$ & $\mathrm{Co}=\frac{1}{D_{h}} \sqrt{\frac{4 \sigma}{g\left(\rho_{l}-\rho_{v}\right)}}$ & $\begin{array}{l}\text { The criterion that enables the determination of the } \\
\text { critical size of the channel defining the shift from } \\
\text { isolated bubble regime to confined bubble regime } \\
\text { for a given fluid pressure }\end{array}$ \\
\hline Eotvos number & Eo $=\frac{(2 \pi)^{2} \sigma}{\left(\rho_{l}-\rho_{v}\right) D_{h}^{2} g}$ & $\begin{array}{l}\text { Ratio of capillary pressure to inter-phase } \\
\text { differential hydrostatic head }\end{array}$ \\
\hline $\mathrm{Nu}$ (Nusselt number) & $\alpha d_{e} / k$ & $\begin{array}{l}\text { Ratio of the convective heat transfer coefficient } \\
\text { to the conductive heat transfer coefficient }\end{array}$ \\
\hline We (Weber number) & $\left(G^{2} L / \rho \sigma\right)$ & $\begin{array}{l}\text { It is a measure of the relative importance of the } \\
\text { fluid's inertia compared to its surface tension }\end{array}$ \\
\hline $\begin{array}{l}\mathrm{Nu}_{f} \text { (Film Nusselt } \\
\text { number) }\end{array}$ & $(\alpha \delta / k)$ & $\begin{array}{l}\text { Ratio of the convective heat transfer coefficient } \\
\text { to the conductive heat transfer coefficient for film }\end{array}$ \\
\hline
\end{tabular}


surface tension dominates, and this marks the boundary for small passages. Triplett et al (1999) found that stratified flow became impossible when Eo > 100 in their experiments indicating size effects. Akbar et al (2003) summarized the previous studies and concluded that the buoyancy effect can be negligible when the Bond number is less than 0.3 where flow regimes are insensitive to the channel orientation.

In fact, all the above dimensionless numbers, Co, Eo and Bo (reported in table 3), consider a combined effect of fluid density, surface tension and channel size on two-phase flow in associating a scale for the system under various experimental conditions.

\subsection{Flow regimes}

The flow pattern maps available in literature were first developed for the petrochemical industry (Baker 1954) for flow of oil and gas in large diameter pipes. Subsequently, the adiabatic flow pattern maps were developed as general flow pattern maps (e.g. Taitel et al 1980). In recent years, a number of flow pattern maps have been developed for specific conditions such as small diameter tubes, evaporation or condensation, compact heat exchanger geometries, etc.

For large diameter tubes, although the generalized flow pattern map for an air-water system, developed by Mandhane et al (1974) specifically for horizontal tubes, was to a large extent, representative of other flow conditions as well, the theoretically based transition criteria presented by Taitel \& Dukler (1976) is one of the most widely used flow pattern maps today. Whereas Hewitt \& Roberts (1969) developed flow regime map for vertical flow as shown in figure 4, for wide range of flow rates and the fact that they correlated both air/water data at atmospheric pressure and steam/water flow at high pressure. Hewitt (2000) gives a comprehensive summary

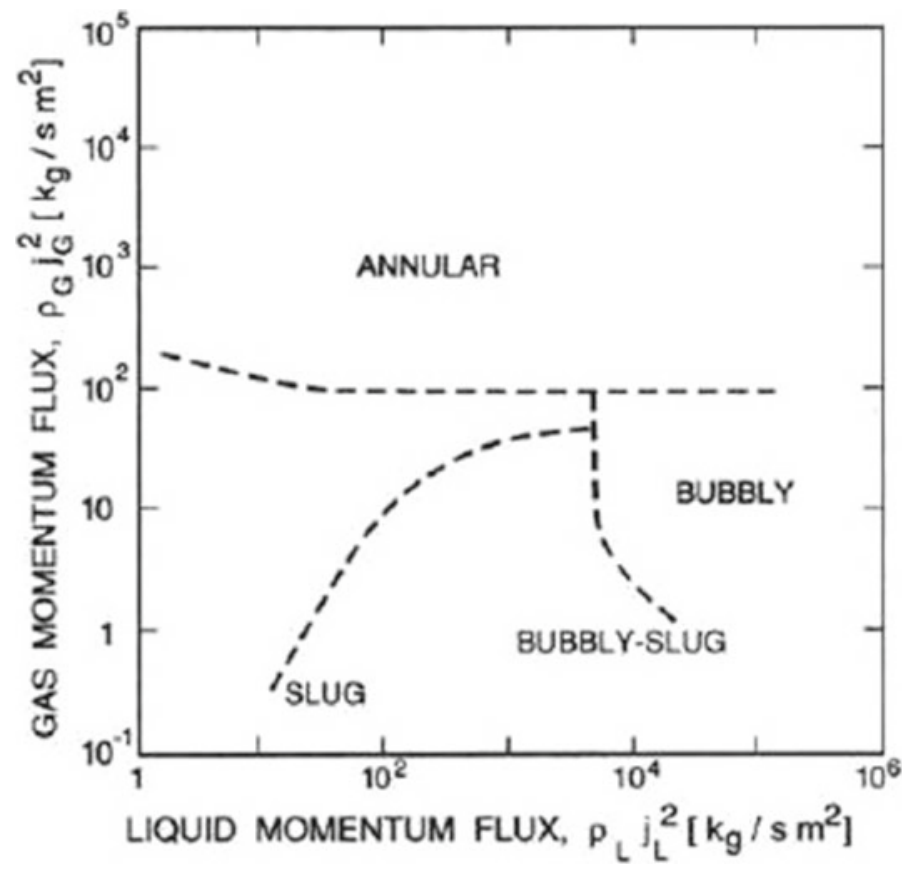

Figure 4. Flow regime map for Hewitt \& Roberts (1969) for vertical channel validated for air-water at atmospheric pressure and steam-water at high pressure. 


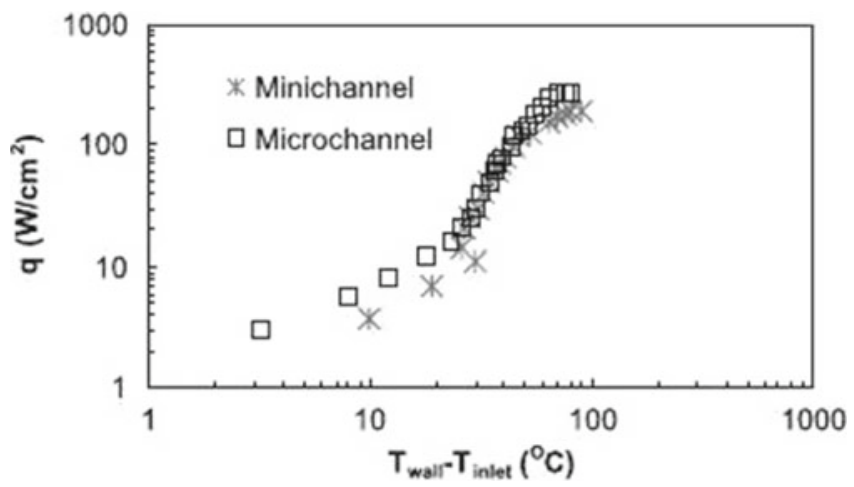

Figure 5. Flow boiling characteristics in mini and microchannel evaporator (Bowers \& Mudawar 1994).

of flow pattern studies available in literature. He noted that both evaporation and condensation processes have a significant effect on the flow patterns. During evaporation, the annular film eventually dries out. For condensations no dry out occurs; the condensate at the wall coats the tube perimeter with the liquid film. The effect of evaporation on the flow pattern transitions was considered to be quite small in large diameter tubes. This is one of the reasons why the flow pattern studies from gas-liquid systems, such as air and water, were extended to the case of evaporation. In smaller diameter tubes, the effect of evaporation could be quite significant. The evaporation of the liquid phase affects the flow in two ways. First, it alters the pressure drop characteristics by introducing an acceleration pressure drop component that can be quite large at higher heat fluxes. Secondly, the tube dimension is quite small, and the effects of surface tension forces become more important in defining the two-phase structure. Bowers \& Mudawar (1994) studied the flow boiling in a minichannel $2.54 \mathrm{~mm}$ diameter and microchannel $510 \mu \mathrm{m}$ diameter. Boiling curves for the two channels were obtained at nearly equal values of liquid Reynolds number. Their results are shown in figure 5. Despite the large variation in the tube diameter, the two curves overlap in the boiling region. It was believed that these experiments fall under the fully developed nucleate boiling regime. The differences between the two boiling curves are only evident at low heat flux (near single-phase region) and high heat flux values (approaching $\mathrm{CHF}$ condition). This indicated that in spite of the differences in the flow characteristics of the channels, the flow boiling behaviour is quite similar in the two geometries.

Experimental observations by various researchers have shown that three flow regimes are sufficient to describe the patterns observed. These have been defined as follows:

2.3a Isolated bubble flow: Similar to bubble flow in large channels, bubbles detach from the nucleation sites and flow as discrete units in the liquid. As the flow proceeds further heat addition results in an increase in the number and size of the bubbles.

2.3b Confined bubble flow: Bubbles span the gap (in spaces confined in one dimension) or fill the channel (in spaces confined in two dimensions). They are separated from the wall by a layer of liquid which evaporates and causes the bubble to grow exponentially. Either through coalescence or through individual growth, single bubbles may reach a sufficient size to be regarded as confined before becoming detached from their nucleation sites. This latter phenomenon has been observed in relatively large tubes having polished surfaces and has been referred to as slug flow. 
A similar phenomenon also occurs in the boiling of liquid metals. The rapid growth of confined bubbles can lead to significant fluctuations in the pressure at entry to the channel and apparent instability in multi-channel arrangements.

2.3c Annular-slug flow: As the confined bubbles expand, liquid in the slugs between them is deposited on the channel wall and the flow becomes annular with random, irregular slugs of liquid inter-spread with the vapour.

Though there are still arguments on the classification schemes of the flow patterns, each class could be subdivided into subclasses. For example, Taitel (1990) and Barnea (1987) defined six typical flow patterns in their vertical upward flow pattern map (figures 6a-b):

- Dispersed bubble: numerous small bubbles float in a continuous liquid phase.

- Bubbly: bubble size is comparable to channel size but not as large as the tube diameter.

- Slug: bubbles develop into bullet shape due to the tube wall restriction. Sometimes the bullet bubbles are followed by a stream of small bubbles creating a trail.

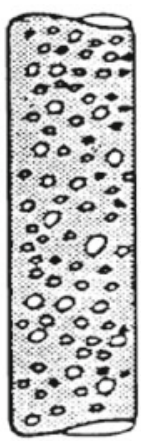

(a)

Bubble flow

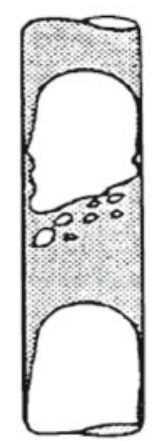

Slug or plug flow

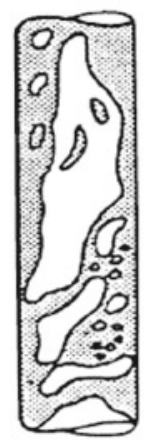

Churn flow

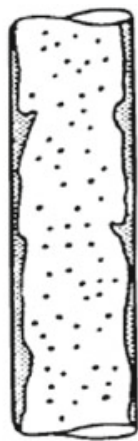

Annular flow

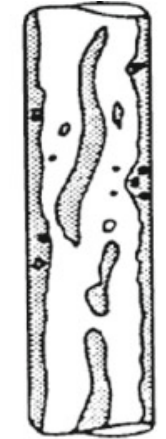

Wispy annular flow

(b) Dispersed bubble
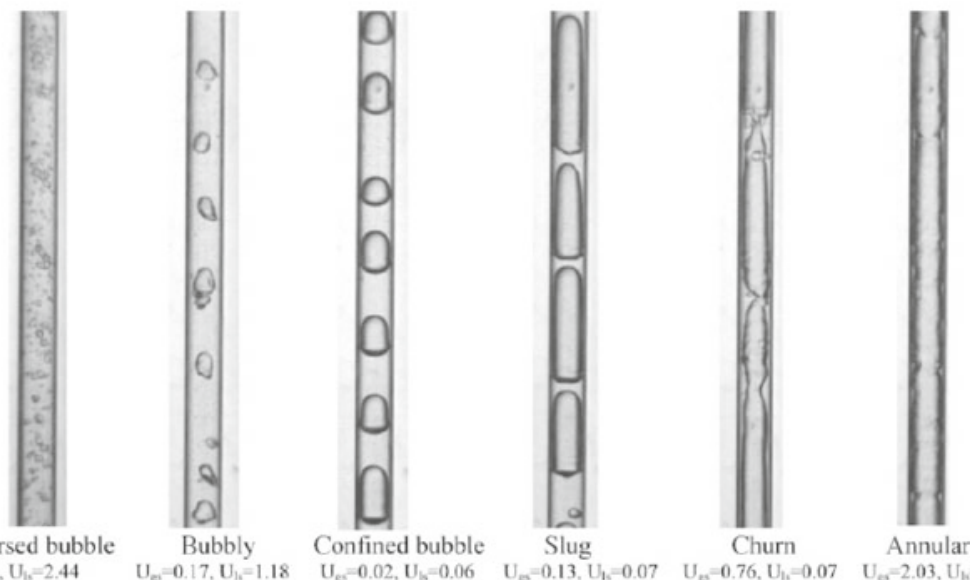

$\mathrm{U}_{\mathrm{e}}=0.17, \mathrm{U}_{\mathrm{l}}=1.18$

$\mathrm{U}_{\mathrm{e}=0}=0.02, \mathrm{U}_{\mathrm{s}}=0.06$

$=0.13, U_{\mathrm{k}}=0.07 \quad \mathrm{U}_{\mathrm{e}}=0.76, \mathrm{U}_{\mathrm{k}}=0.07$

(1, $=2.03, U_{h}=0.07$

Figure 6. (a) Flow patterns in vertical flow (Hewitt 2007). (b) Experimental observation of $2.01 \mathrm{~mm}$ vertical tube observed by Shiferaw et al (2009). 
Table 4. Flow behaviour reported in literature for tubes and channels of various sizes.

\begin{tabular}{|c|c|c|}
\hline References & Passage size and fluid & Flow behaviour reported \\
\hline Barnea (1987) & $\begin{array}{l}4-12 \mathrm{~mm} \text { tubes } \\
\text { Air-water }\end{array}$ & $\begin{array}{l}\text { Dispersed bubble, elongated bubble, slug, churn } \\
\text { and annular }\end{array}$ \\
\hline $\begin{array}{l}\text { Damianides \& } \\
\text { Westwater (1988) }\end{array}$ & $1-5 \mathrm{~mm}$ tubes & $\begin{array}{l}\text { Dispersed bubble, bubbly, plug, slug, pseudo slug, } \\
\text { wavy and annular }\end{array}$ \\
\hline $\begin{array}{l}\text { Mishima \& Hibiki } \\
\text { (1996) }\end{array}$ & $\begin{array}{l}1-4 \mathrm{~mm} \text { tubes } \\
\text { Air - water }\end{array}$ & Bubbly, slug, churn, annular and annular-mist flow \\
\hline $\begin{array}{l}\text { Kew \& Cornwell } \\
(2000)\end{array}$ & $\begin{array}{l}1.39 \text { and } 3.69 \mathrm{~mm} \text { tubes } \\
\mathrm{R} 141 \mathrm{~b} \text { flow boiling }\end{array}$ & $\begin{array}{l}\text { Isolated bubble, confined bubble and slug/ } \\
\text { annular flow }\end{array}$ \\
\hline Lin et al (1999) & $\begin{array}{l}0.5-4 \mathrm{~mm} \text { tubes } \\
\text { Air-water }\end{array}$ & Bubbly, confined bubble, slug, churn and annular \\
\hline Triplett et al (1999) & $\begin{array}{l}1.1 \text { and } 1.45 \mathrm{~mm} \text { tube } \\
1.097,1.49 \mathrm{~mm} \\
\text { semi-triangular } \\
\text { microchannel }\end{array}$ & $\begin{array}{l}\text { Bubbly, slug, aerated slug-churn, slug-annular, } \\
\text { annular }\end{array}$ \\
\hline \multirow[t]{2}{*}{ Zhao \& Bi (2001) } & \multicolumn{2}{|c|}{$\begin{array}{l}\text { Triangular channels 2.886, Dispersed bubble, slug, churn, annular } \\
1.443,0.866 \mathrm{~mm}\end{array}$} \\
\hline & Air-water & Dispersed flow was not present in the $0.866 \mathrm{~mm}$ \\
\hline Serizawa et al (2002) & $\begin{array}{l}0.02,0.025,0.05 \text { and } \\
0.1 \mathrm{~mm} \text { tubes } \\
\text { Air-water }\end{array}$ & $\begin{array}{l}\text { Bubbly, slug, liquid ring flow, liquid lump flow. } \\
\text { Lump flow was not observed when using } \\
\text { steam-water }\end{array}$ \\
\hline Kawahara et al (2002) & $\begin{array}{l}0.1 \mathrm{~mm} \text { tube } \\
\text { Nitrogen - deionised water }\end{array}$ & $\begin{array}{l}\text { Liquid alone and gas core with (i) smooth-thin } \\
\text { liquid film (ii) smooth-thick liquid film (iii) ring } \\
\text { shaped liquid film (iv) deformed interface }\end{array}$ \\
\hline Chung \& Kawaji (2004) & $\begin{array}{l}0.05 \text { to } 0.53 \mathrm{~mm} \text { tubes } \\
\text { Nitrogen-water }\end{array}$ & $\begin{array}{l}\text { Bubbly, churn, gas core flow with smooth thin } \\
\text { liquid film. Slug-annular, annular. Churn } \\
\text { observed only in } 0.25 \text { and } 0.53 \mathrm{~mm}\end{array}$ \\
\hline Chen \& Garimella (2006) & $\begin{array}{l}1.1,2.01,2.88 \text { and } \\
4.26 \mathrm{~mm} \text { tubes } \\
\text { R134a }\end{array}$ & $\begin{array}{l}\text { Dispersed bubble, bubbly, slug, churn, annular } \\
\text { and mist flow. Confined flow was observed } \\
\text { in the } 2.01 \text { and } 1.1 \mathrm{~mm} \text { tubes }\end{array}$ \\
\hline $\begin{array}{l}\text { Revellin \& Thome } \\
\text { (2007) }\end{array}$ & 0.51 and $0.8 \mathrm{~mm}$ tubes & Isolated bubble, coalescing bubble and annular flow \\
\hline Shiferaw et al (2007) & $\begin{array}{l}\text { Circular } 2.01 \text { and } \\
4.26 \mathrm{~mm} \\
\text { R134 }\end{array}$ & Slug, churn and annular \\
\hline Shiferaw et al (2009) & Circular - $1.1 \mathrm{~mm}, \mathrm{R} 134 \mathrm{a}$ & Confined, slug, churn, annular \\
\hline Julia et al (2011) & $\begin{array}{l}\text { Vertical annular - } 19 \mathrm{~mm} \\
\text { Air - Water }\end{array}$ & $\begin{array}{l}\text { Bubbly, cap-slug, churn-turbulent and annular flows, } \\
\text { axial and radial flow regime transitions studied } \\
\text { and surveyed }\end{array}$ \\
\hline Tadrist (2007) & $\begin{array}{l}\text { Circular } 10 \mathrm{~mm} \\
\text { and higher }\end{array}$ & $\begin{array}{l}\text { Flow instabilities studied and analysed for mini } \\
\text { and macrochannels }\end{array}$ \\
\hline Zhang et al (2010) & $\begin{array}{l}\text { Circular } 1-5 \mathrm{~mm} \text {, } \\
\text { refrigerents-vapour, } \\
\text { ammonia-vapour, } \\
\text { water-air }\end{array}$ & $\begin{array}{l}\text { Reported that void fraction and pressure drop } \\
\text { correlations based on separated flow model work } \\
\text { better in comparison with homogeneous flow } \\
\text { model for flow boiling in minichannels }\end{array}$ \\
\hline Venkatesan et al (2010) & $\begin{array}{l}\text { Circular } 0.6-3 \mathrm{~mm} \text {, } \\
\text { air-water }\end{array}$ & $\begin{array}{l}\text { Bubbly, dispersed bubbly, slug, slug-annular, } \\
\text { and wavy-annular flow. Unique flow patterns } \\
\text { were identified for different tube diameters } \\
\text { that confirm the diameter effect on flow patterns } \\
\text { in two-phase flows }\end{array}$ \\
\hline
\end{tabular}


Table 4. (continued).

\begin{tabular}{|c|c|c|}
\hline References & Passage size and fluid & Flow behaviour reported \\
\hline Zhihu et al (2006) & $\begin{array}{l}\text { Circular } 50 \mathrm{~mm} \text { with } \\
\text { horizontal rod, } \\
\text { air - water }\end{array}$ & $\begin{array}{l}\text { Rod affects flow transitions and bubble shape and } \\
\text { size. All standard regimes observed }\end{array}$ \\
\hline $\begin{array}{l}\text { Ould Didi et al } \\
\text { (2002) }\end{array}$ & $\begin{array}{l}\text { Circular } 10.92-12 \mathrm{~mm} \text {, } \\
\text { horizontal tube, R134a, } \\
\text { R123, R402A, R404A } \\
\text { and R502 }\end{array}$ & $\begin{array}{l}\text { Best method for pressure drop prediction reported } \\
\text { for each type of flow pattern. A single best } \\
\text { correlation applicable for all flow regimes attempted } \\
\text { but with high deviations }\end{array}$ \\
\hline $\begin{array}{l}\text { Karayiannis et al } \\
\text { (2008) }\end{array}$ & $\begin{array}{l}0.52-4.26 \mathrm{~mm} \\
\text { Vertical tubes, R134a }\end{array}$ & $\begin{array}{l}\text { Above } 0.52 \mathrm{~mm} \text { dia. pressure drops were predicted } \\
\text { well by Chisholm and the Lockhart-Martinelli method. } \\
\text { No existing correlation predicted well for } 0.52 \mathrm{~mm} \text { dia. }\end{array}$ \\
\hline
\end{tabular}

- Churn: bullet bubbles start to distort and small bubbles in liquid slug coalesce into gas clump with increase of gas velocity. It is a highly oscillatory flow with chaotic interface.

- Annular: gas phase becomes a continuous flow in the core of the tube.

- Mist: liquid film is blown away from tube wall and numerous liquid droplets float in highspeed vapour flow.

Flow behaviour reported in literature for tubes and channels of various sizes are reported in table 4.

Harirchian \& Garimella (2010) reviewed the literature on flow regime maps for boiling in microchannels. They developed a new type of comprehensive flow regime map for wide range of experimental parameters and channel dimensions. They also developed quantitative transition criteria of flow regime based on non-dimensional parameters (figure 7). This comprehensive flow regime map is based on experimental results and flow visualization performed with Fluorinert FC-77.

The factors affecting flow patterns are numerous and complex. Within the transition zone the flow patterns possess characteristics of more than one of the flow patterns. Despite significant research in development of flow maps with similar tubes as well as similar experimental conditions, it is observed that studies are not in agreement with each other (for e.g., Oya 1971, Barnea et al 1983 and Mishima \& Hibiki 1996). This is because the identification of flow patterns may be greatly affected by the observer's subjectivity and the experimental technique employed.

\subsection{Two-phase pressure drop}

The prediction of two-phase pressure gradient is an essential step in the design of a variety of plant in the power and process industries. The total pressure drop of fluid is due to the variation of kinetic and potential energy of the fluid and also due to friction at the wall of flow channel (see Equation 8). Calculation of pressure drop across the full length of the heated channel is more complex due to the existence of several regimes with varied physical conditions along the channels.

$$
\Delta P_{\text {Total }}=\Delta P_{\text {static }}+\Delta P_{\text {momentum }}+\Delta P_{\text {frictional }} \text {. }
$$

The most significant and difficult term is the frictional pressure drop. In order to get frictional pressure drop one should have a knowledge of two-phase friction factor, mixture density, vapour 


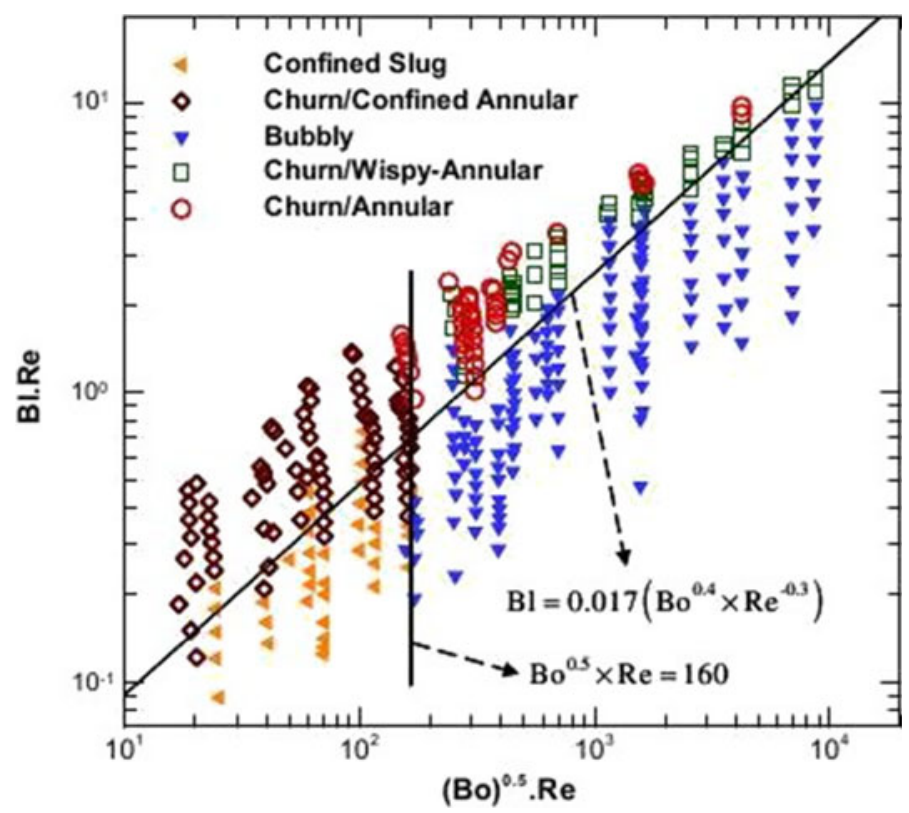

Figure 7. Comprehensive flow regime map for FC-77.

quality and void fraction, velocity of vapour and liquid (i.e., slip ratio) as shown in figure 8. It has been shown that total pressure drop is the summation of acceleration, static and frictional pressure drop. If acceleration and static pressure drop are present (figure 8), judicious selection of void fraction correlation becomes necessary for reliable quantitative measurements of these two pressure drops. Similarly, from figure 9, it can be seen that frictional pressure drop is estimated by various concepts such as in adiabatic and diabatic two-phase flows. Two-phase pressure drop can be measured for gas-liquid adiabatic flow or it can also be measured for vapour-liquid non-adiabatic, boiling or condensing flow. Because of ease of operation, laboratory measurements tend to be made with adiabatic gas-liquid flow e.g., air-water, rather than non-adiabatic flow. Two-phase pressure drop correlations are largely based on data for such adiabatic gasliquid two-phase flow. On the other hand, two-phase heat transfer equipment, by default, will have boiling or condensing flows. It is generally accepted that the two-phase pressure drop and flow pattern characteristics for non-adiabatic flow could be similar to adiabatic gas-liquid flow. Adiabatic two-phase frictional pressure drop is developed from empirical correlations, friction multiplier concepts and flow pattern specific models. Few correlations considering two-phase friction multiplier concept have been reported in table 5 .

Whalley (1980) made an extensive comparison based on frictional multiplier concept between various published correlations. Following are his recommendations:

- $\left(\frac{\mu_{L}}{\mu_{G}}\right)<1000$ and mass velocities less than $2000 \mathrm{~kg} / \mathrm{m}^{2} \mathrm{~s}$, the Friedel correlation (Friedel 1979) should be used.

- $\left(\frac{\mu_{L}}{\mu_{G}}\right)>1000$ and mass velocities greater than $100 \mathrm{~kg} / \mathrm{m}^{2} \mathrm{~s}$, the Chisholm correlation (Chisholm 1973) should be used. 


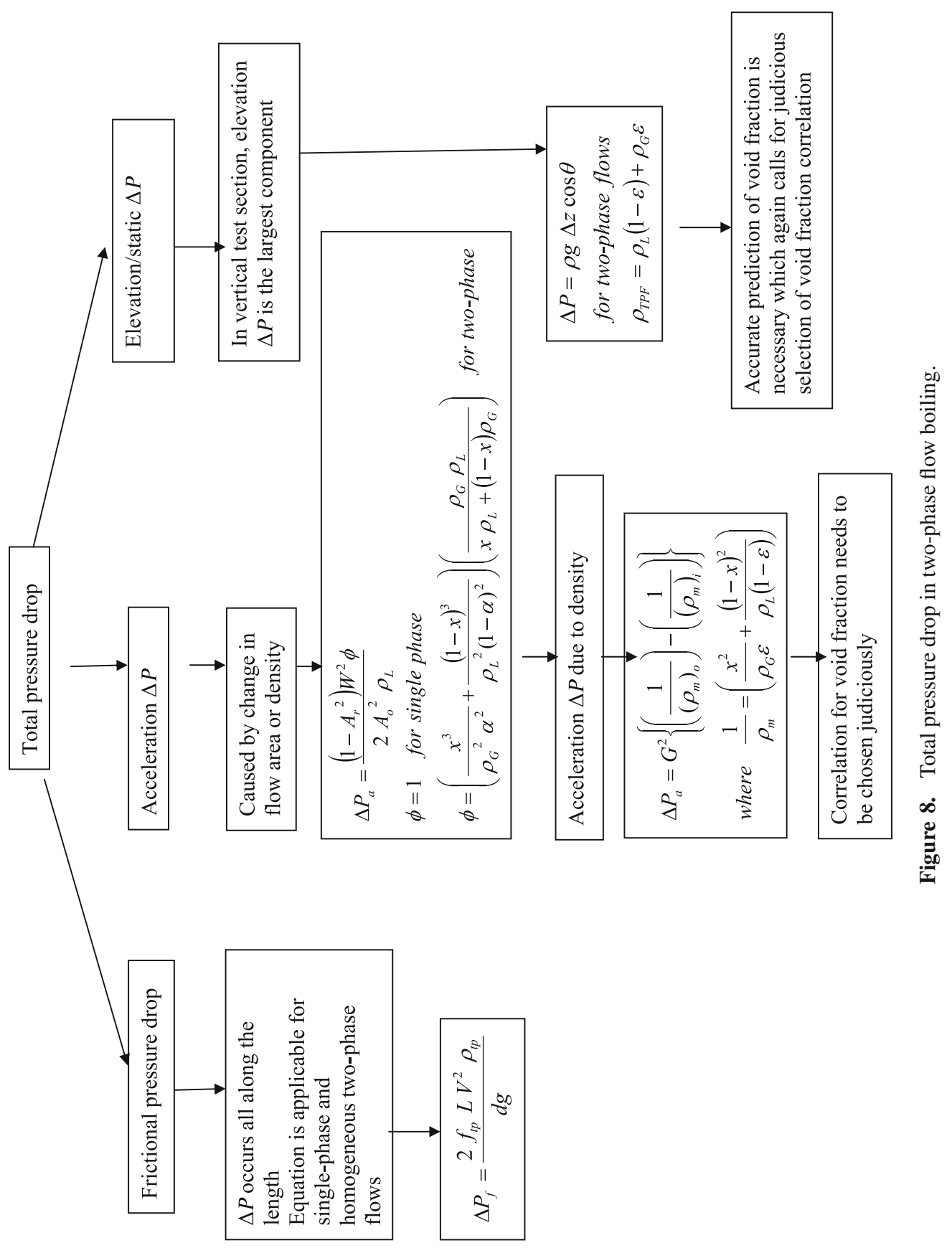




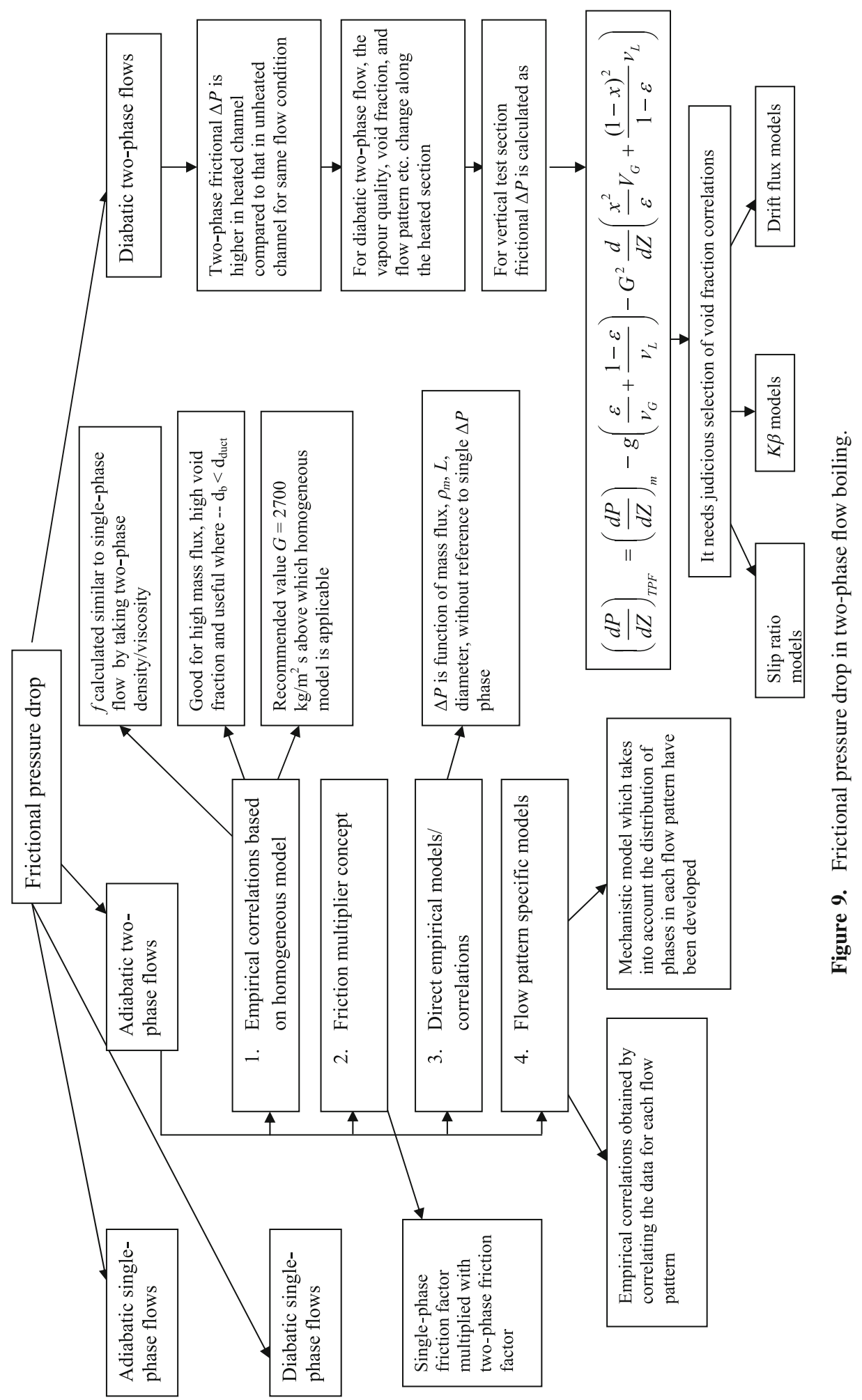


Table 5. Correlations for two-phase frictional pressure drop.

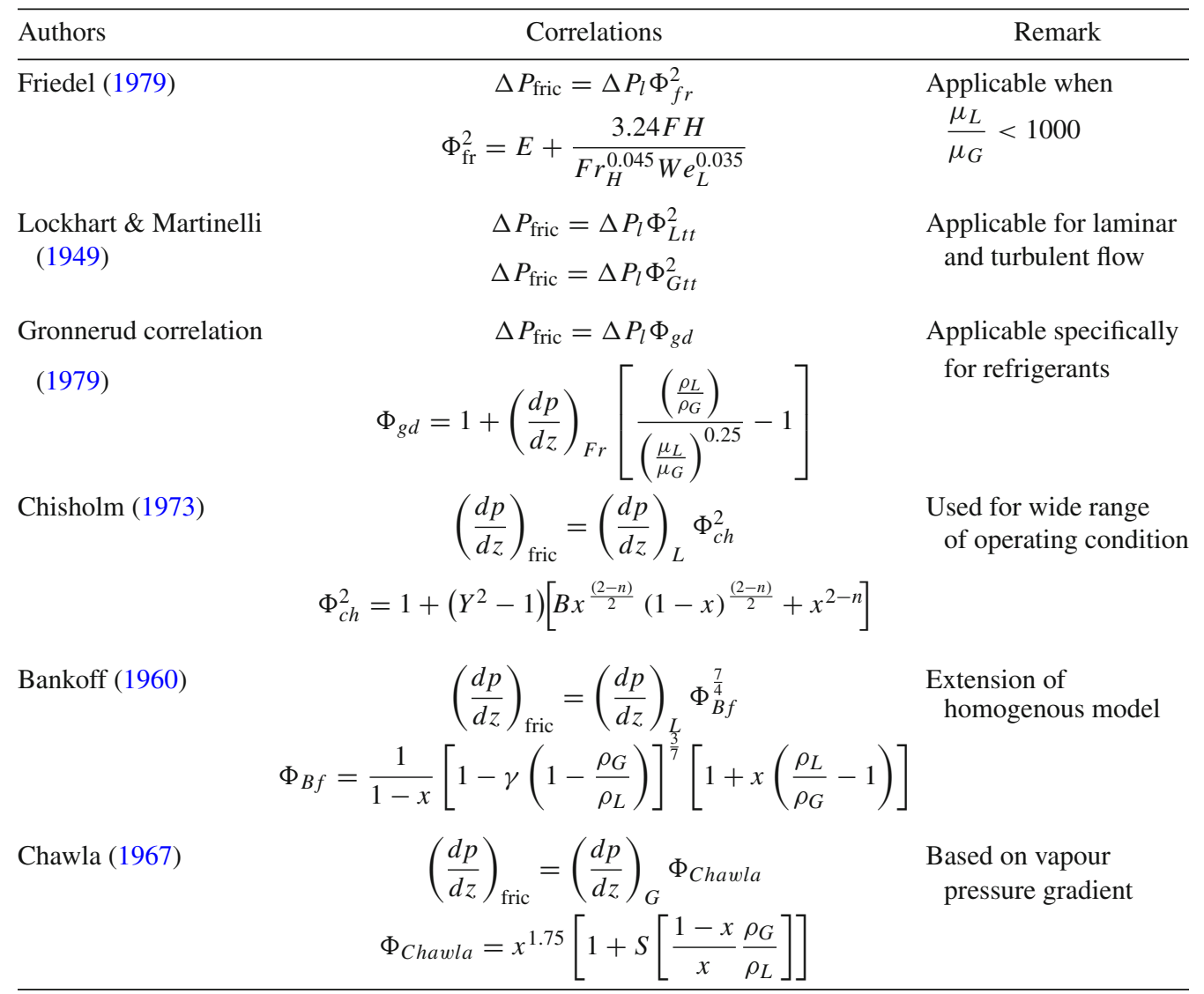

- $\left(\frac{\mu_{L}}{\mu_{G}}\right)>1000$ and mass velocities less than $100 \mathrm{~kg} / \mathrm{m}^{2} \mathrm{~s}$, the Lockhart and Martinelli correlation (Lockhart \& Martinelli 1949) should be used.

- For most fluids, $\left(\frac{\mu_{L}}{\mu_{G}}\right)<1000$ and hence the Friedel correlation will be the preferred method for in tube flow according to Whalley (1980).

In case of diabatic two-phase flows, frictional pressure drop is a function of flow properties and significantly on void fraction as shown in figure 9. It is observed that vapour quality and void fraction parameters are continuously changing. This affects overall flow pattern (refer to section 2.3) and thus affects pressure drop of the system.

Therefore, it is important to distinguish the difference between void fraction of vapour phase and thermodynamic vapour quality. The vapour quality is the ratio of mass of vapour to the total mass of liquid plus vapour. The most widely utilized void fraction definition is the cross sectional average void fraction, which is based on the relative cross sectional areas occupied by the respective phases. 
Thermodynamic vapour quality and void fraction are closely related to each other. The classic definition of $x$ as a mass flow rate ratio clearly shows that it includes slip ratio $S$ using equation 4 . This phase velocity ratio or slip ratio is defined as the cross sectional areas of mean vapour velocity to cross sectional area mean liquid velocity.

$$
\begin{aligned}
x & =\frac{m_{v}}{m_{v}+m_{l}} . \\
x & =\frac{u_{v} \rho_{v} A_{c} \alpha}{\left[u_{v} \rho_{v} A_{c} \alpha+u_{l} \rho_{l} A_{c}(1-\alpha)\right]} . \\
x & =\frac{\rho_{v} \alpha S}{\left[\rho_{v} \alpha S+\rho_{l}(1-\alpha)\right]} . \\
\alpha & =\frac{1}{\left\{1+S(1-x) \frac{\rho_{v}}{\rho_{l}}\right.} . \\
x & =\frac{\rho_{v} \alpha}{\rho_{m}} \\
\rho_{m} & =(1-\alpha) \rho_{l}+\alpha \rho_{v} .
\end{aligned}
$$

Thus, there is a direct connection between void fraction and thermodynamic quality through mixture densities. It is evident that actual vapour mass fraction, which corresponds to the actual void fraction is equivalent to thermodynamic vapour quality.

This cross sectional void fraction is usually predicted by one of the following methods:

- Homogeneous model (which assumes the two-phases travel at the same velocity).

- 1-D models (which account for differing velocities of the two-phases).

- Drift flux models including radial variations in local void fraction and flow velocity.

- Models based on the physics of specific flow regimes.

- Empirical and semi empirical methods.

Thus, relation between void fraction and vapor quality represented by several correlations; few of them are reported in Table 6 . Where it observed that void fraction is function of vapor quality.

Industrial applications, where two-phase flow exists, requires the formidable task of predicting the phase distribution in the system, given their operating conditions. Once this phase distribution is known, the problem may be simplified. One of the critical unknown parameters involved in predicting the pressure loss and heat transfer in any gas-liquid system is the void fraction $(\varepsilon)$ or the liquid holdup $(1-\varepsilon)$. $\varepsilon$ is the volume occupied by the gas and $(1-\varepsilon)$ is the volume occupied by the liquid. The accurate prediction of void fraction in vertical channels is of immense importance in determining the two-phase pressure drop. This variation in void fraction resulting from the change in flow direction requires a reliable, accurate, and flexible correlation to predict void fraction. Many researchers have contributed to the development of the void fraction correlations in vertical orientation. The theoretical considerations used for the development of these correlations are based on the separated flow model or the drift flux model. Most of these correlations are flow pattern-specific and are limited in their application in terms of the range of flow variables. The void fraction correlation proposed by Woldesemayat (2006), is independent of the flow direction, system pressure, and fluid thermo-physical properties. However, it is subject to some inaccuracies in predicting the void fraction $(\varepsilon)$ typically in the range of $0<\varepsilon<$ 0.4 in vertical upward flow directions. To choose the right correlation for the desired application from a pool of available correlations in the literature (Godbole et al 2011), it is of the utmost importance to sort out and identify the top-performing correlations applicable to a range of flow 
Table 6. Void fraction correlations.

\begin{tabular}{|c|c|}
\hline Author & Correlations \\
\hline \multicolumn{2}{|l|}{ Slip ratio models } \\
\hline Homogeneous & $\varepsilon=\left[1+\left(\frac{1-x}{x}\right)\left(\frac{\rho_{G}}{\rho_{L}}\right)\left(\frac{\mu_{L}}{\mu_{G}}\right)\right]^{-1}$ \\
\hline Lockhart \& Martinelli (1949) & $\varepsilon=\left[1+0.28\left(\frac{1-x}{x}\right)^{0.04}\left(\frac{\rho_{G}}{\rho_{L}}\right)^{0.50}\left(\frac{\mu_{L}}{\mu_{G}}\right)^{0.07}\right]$ \\
\hline Chisholm (1973) & $\varepsilon=\left[1+\sqrt{\left.1-x\left(1-\frac{\rho_{L}}{\rho_{G}}\right)\left(\frac{1-x}{x}\right)\left(\frac{\rho_{G}}{\rho_{L}}\right)\right]}\right.$ \\
\hline Spedding \& Chen (1984) & $\varepsilon=\left[1+2.22\left(\frac{1-x}{x}\right)^{0.0 J}\left(\frac{\rho_{G}}{\rho_{L}}\right)^{0.0 J}\right]$ \\
\hline Chen (1986) & $\varepsilon=\left[1+0.18\left(\frac{1-x}{x}\right)^{0.6}\left(\frac{\rho_{G}}{\rho_{L}}\right)^{0.33}\left(\frac{\mu_{L}}{\mu_{G}}\right)^{0.07}\right]^{-1}$ \\
\hline Hamersma \& Hart (1987) & $\varepsilon=\left[1+0.26\left(\frac{1-x}{x}\right)^{0.0 /}\left(\frac{\rho_{G}}{\rho_{L}}\right)^{0.30}\right]$ \\
\hline Zhao et al (2000) & $\varepsilon=\left[1+\varepsilon^{-0.125}\left(\frac{1-x}{x}\right)^{0.875}\left(\frac{\rho_{G}}{\rho_{L}}\right)^{0.875}\left(\frac{\mu_{L}}{\mu_{G}}\right)^{0.875}\right]^{-1}$ \\
\hline \multicolumn{2}{|l|}{$K \varepsilon_{H}$ correlations } \\
\hline Chisholm (1983), Armand (1946) & $\varepsilon=\frac{1}{\varepsilon_{H}+\frac{1}{\left(1-\varepsilon_{H}\right)^{0.5}}} \varepsilon_{H}$ \\
\hline Bankoff (1960) & $\varepsilon=\left[0.71+\left(1.45 \times 10^{-2}\right) P\right] \varepsilon_{H}$ \\
\hline \multicolumn{2}{|l|}{ Drift flux correlations } \\
\hline Hughmark (1965) & $\varepsilon=\frac{U_{S G}}{1.2 U_{M}}$ \\
\hline Rouhani \& Axelsson (1970) & $\varepsilon=\frac{x}{\rho_{G}}\left[\operatorname{CO}\left(\frac{x}{\rho_{G}}+\frac{1-x}{\rho_{L}}\right)+\frac{U_{G M}}{G}\right]^{-1}$ \\
\hline
\end{tabular}

variables and channel orientations. Some of the most cited correlations are reported in table 6. In the present study, few correlations compared (with water and $n$-pentane as working fluid) and concluded that as vapour quality increases void fraction is also increased (see figures $10 \mathrm{a}-\mathrm{b}$ ).

\subsection{Heat transfer coefficient}

In vertical channel two phase flow system, boiling will not occur until the wall temperature reaches a certain value (wall superheat) above the saturation temperature. As soon as evaporation of fluid starts, there is qualitatively progressive variation in local heat transfer coefficient along the heated tube because of variation in flow regimes (as discussed in section 1). Based on analyses of various experimental investigations of flow boiling, it was found that liquid-laminar 


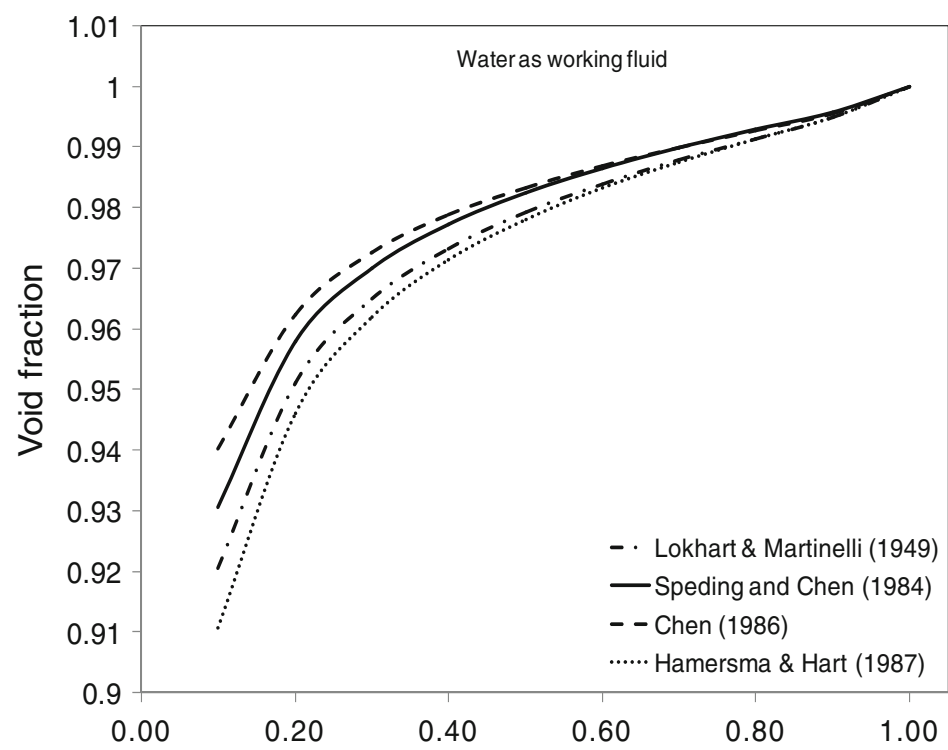

(a) Vapour quality, $\mathrm{x}$

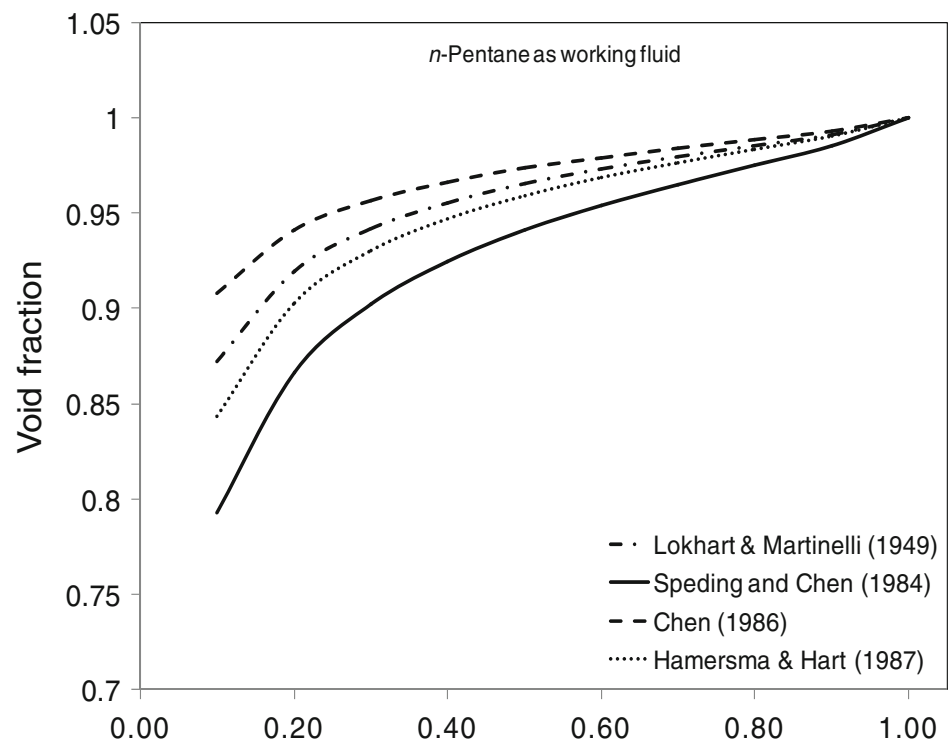

(b)

Vapour quality, $x$

Figure 10. (a) Comparison of homogeneous model correlations using water as working fluid. (b) Comparison of homogeneous correlations using $n$-pentane as working fluid.

and gas-turbulent flow is a common feature in many applications of small channels. Therefore, many researchers formulated various heat transfer coefficient correlations and are as follows:

$$
h_{t p}=S h_{n b}+F h_{s p}
$$


where

$$
\begin{aligned}
& \text { for } \begin{array}{rl}
\frac{1}{X_{t t}}>0.1 & F=2.35\left(\frac{1}{X_{t t}}+0.213\right)^{0.736} \\
\text { for } \quad \frac{1}{X_{t t}}<0.1 \quad & F=1
\end{array} \\
& h_{s p}=0.023 \operatorname{Re}_{f}^{0.8} \operatorname{Pr}_{f}^{0.4}\left(\frac{k_{f}}{D_{h}}\right) \\
& S=\frac{1}{\left(1+2.53 \times 10^{-6} \operatorname{Re}_{f}^{1.17}\right)} \\
& h_{n b}=0.00122\left(\frac{k_{f}^{0.79} C_{p f}^{0.45} \rho_{f}^{0.49}}{\sigma^{0.5} \mu_{f}^{0.29} h_{f g}^{0.24} \rho_{g}^{0.24}}\right) \Delta T_{\text {sat }}^{0.24} \Delta P_{\text {sat }}^{0.75} \\
& X_{t t}=\left(\frac{1-x_{e q}}{x_{e q}}\right)\left(\frac{\rho_{g}}{\rho_{f}}\right)^{0.5}\left(\frac{\mu_{f}}{\mu_{g}}\right)^{0.1} .
\end{aligned}
$$

Here Chen introduced two dimensionless factors, the suppression factor $S$ and the enhancement factor $F$, to account for the smaller effective superheat due to forced convection, and for the increase in convective turbulence due to the presence of vapour phase, respectively. This correlation is widely used and taken as a benchmark in the literature.

To correlate flow boiling heat transfer coefficients Shah (1987) proposed a different approach, where the nucleate boiling component was represented by the boiling number Bo, while the convective number Co was used for the forced convection component. He first used a graphical chart, later curve-fitted equations, to select the larger of the two components:

$$
\frac{h_{t p}}{h_{s p}}=\operatorname{MAX}\left(\psi_{n b}, \psi_{f c}\right)
$$

where the nucleate boiling component $\psi_{n b}=f n(\mathrm{Bo})$ and the convective component $\psi_{f c}=$ $f n(\mathrm{Co})$.

After Chen (1963) and Shah (1976) various researchers developed heat transfer coefficient correlations depending upon specific design and operating conditions. We list them below:

- Lazarek and Black (1982):

$$
h_{t p}=\left(30 \mathrm{Re}^{0.857} \mathrm{Bo}^{0.714}\right)
$$

- Modified Lazarek and Black (1982):

$$
h_{t p}=\left\{30 \mathrm{Re}^{0.857} \mathrm{Bo}^{0.714}(1-x)^{-0.143}\right\} k / L
$$

- Cooper correlation: Cooper (1984) proposed the following correlation for nucleate boiling heat transfer.

$$
h_{n b}=55 P_{R}^{0.12-0.087 \ln \varepsilon}\left(-0.4343 \ln P_{R}\right)^{-0.55} M^{-0.5} q^{0.67}
$$

- Gungor and Winterton correlation: Gungor \& Winterton (1986) proposed a correlation that is a modification of the Chen correlation:

$$
h_{t p}=S h_{n b}+F h_{s p}
$$


where

$$
S=f n\left(F, \operatorname{Re}_{f}\right) \quad \text { and } \quad F=f n\left(\mathrm{Bo}, X_{t t}\right)
$$

- Liu \& Winterton (1991) pointed out the deficiencies of Gungor and Winterton (1986) correlation and developed a general correlation for flow boiling in tubes

$$
h_{t p}=\left[\left(F h_{s p, f o}\right)^{2}+\left(S h_{n b}\right)^{2}\right]^{1 / 2}
$$

- Kandlikar (1990) proposed a correlation of the form

$$
h_{t p}=h_{s p}\left(C_{1} \mathrm{Co}^{C_{2}}\left(25 \mathrm{Fr}_{f o}\right)^{C_{5}}+C_{3} \mathrm{Bo}^{C_{4}} F_{f}\right) .
$$

Corresponding to the forced convection and nucleate boiling regions, two sets of constants $C_{1}$ through $C_{5}$ were established by careful regression analysis, using a large bank of water data. The heat transfer coefficient at any given condition is evaluated using the two sets of constants for the two regions, and the higher of the two heat transfer coefficient values is the choice. In addition, when tested on a refrigerant, a fluid-dependent correction factor $F_{f}$ is introduced. Therefore a new factor $F_{f}$ is needed when this correlation is used for any new fluid beyond the tested ones.

Steiner \& Taborek (1992) followed the power-type addition model for two boiling components and built a heat transfer correlation for flow boiling based on an extensive databank that is similar to Dittus-Boelter correlation (Dittus \& Boelter 1930).

- Tran et al correlation: Tran et al (1996) conducted flow boiling heat transfer experiments for R12 in small channels and proposed

$$
h_{t p}=840,000 \mathrm{Bo}^{0.6} \mathrm{We}_{l}^{0.3}\left(\rho_{l} / \rho_{g}\right)^{-0.4}
$$

- Kew-Cornwell correlation: Kew \& Cornwell (1997) modified the Lazarek-Black equation to allow for an observed increase in the heat transfer coefficient with the vapour quality in larger tubes.

$$
h_{t p}=30 \operatorname{Re}_{l o}^{0.857} \mathrm{Bo}^{0.714} \frac{\lambda_{l}}{D_{h}}\left(\frac{1}{1-x}\right)^{0.143}
$$

Lin et al (2001) presented a work on four circular and one square channels to measure local heat transfer coefficients at various heat flux and mass flux. It was observed that in circular and rectangular channels local heat transfer coefficients are not only function of heat flux but also a function of vapour quality and weaker function of mass flux.

- Yu et al (2002) modified the correlation suggested by Tran et al and proposed the following instead:

$$
h_{t p}=640,000 \mathrm{Bo}^{0.54} \mathrm{We}_{l}^{0.27}\left(\rho_{l} / \rho_{g}\right)^{-0.2}
$$

- Flow boiling heat transfer correlations, such as those in Kandlikar (2001, 2002), utilize the single-phase, all-liquid heat transfer coefficient in predicting the nucleate boiling and convective boiling components as given by the following equation:

$$
\left(h_{t p} / h_{s p}\right)=\left\{C_{1} \mathrm{Co}^{C_{2}}\left(25 F r_{f o}\right)^{C_{5}}+C_{3} \mathrm{Bo}^{C^{4}} \mathrm{Fr}_{f}\right\}
$$

- Kandlikar-Balasubramanian (2004) extended the above Kandlikar correlation to laminar flow and mini- and microchannels. The flow regions are classified as turbulent region 
$\left(\operatorname{Re}_{L O} \geq 3000\right)$, transition region $\left(1600 \leq \operatorname{Re}_{L O}<3000\right)$ and laminar region $\left(\operatorname{Re}_{L O}<\right.$ 1600). They considered the effect of tube orientation for flow boiling in small diameter tubes negligible, and thus deleted the Froude number effect in the above correlation by setting $f\left(\mathrm{Fr}_{l o}\right)=1$.

$$
\begin{gathered}
h_{t p, n b}=\left[0.6683 \mathrm{Co}^{-0.2}+1058.0 \mathrm{Bo}^{0.7} F_{f}\right](1-x)^{0.8} h_{l o} \\
h_{t p, n b}=\left[1.136 \mathrm{Co}^{-0.9}+667.2 \mathrm{Bo}^{0.7} F_{f}\right](1-x)^{0.8} h_{l o}
\end{gathered}
$$

where $h_{l o}$ is constant for the laminar region, $h_{l o}$ is calculated using Eq. 29 for the turbulent region and determined by linear interpolation in the transition region.

$$
\begin{gathered}
h_{l o}=\frac{(f / 8) \operatorname{Re}_{l o} \operatorname{Pr}_{l}\left(\lambda_{l} / D\right)}{1+12.7(f / 8)^{1 / 2}\left(\operatorname{Pr}_{l}^{2 / 3}-1\right)} \text { for } 10^{4} \leq \operatorname{Re}_{l o} \leq 5 \times 10^{6} \\
h_{l o}=\frac{(f / 8)\left(\operatorname{Re}_{l o}-1000\right) \operatorname{Pr}_{l}\left(\lambda_{l} / D\right)}{1+12.7(f / 8)^{1 / 2}\left(\operatorname{Pr}_{l}^{2 / 3}-1\right)} \text { for } \quad 3000 \leq \operatorname{Re}_{l o} \leq 10^{4} \\
f=\left(0.79 \ln \operatorname{Re}_{l o}-1.64\right)^{-2}
\end{gathered}
$$

$F_{f}$ values are listed in table 7 . The applicable vapour quality range is $x<0.7 \sim 0.8$.

Shiferaw et al (2007) carried out experiments using channel diameter 4.26 and $2.01 \mathrm{~mm}$ and gathered experimental data for local heat transfer coefficient as a function of vapour quality. Basically, heat transfer coefficient is based on prevailing flow regimes. Therefore, Shiferaw et al (2007) showed flow pattern transition boundaries predicted by Chen \& Garimella (2006) with heat transfer coefficient vs vapour quality as shown in figure 11. The experimental results for the $4.26 \mathrm{~mm}$ tube demonstrate that heat transfer coefficient increases with heat flux but does not change with vapour quality when the quality was less than $40-50 \%$ for low heat flux. For $2.01 \mathrm{~mm}$ tube this boundary moves to $20-30 \%$ vapour quality. This behaviour of low quality is conventionally interpreted as evidence that nucleate boiling is the dominant heat transfer mechanism.

Table 7. Recommended $F_{f}$ values in Kandlikar flow boiling correlation.

\begin{tabular}{llll}
\hline Fluid & $F_{f}$ & Fluid & $F_{f}$ \\
\hline Water & 1.00 & R134a & 1.63 \\
R11 & 1.30 & R152a & 1.10 \\
R12 & 1.50 & R31/R-132 & 3.30 \\
R13B1 & 1.31 & R141b & 1.80 \\
R22 & 2.20 & R124 & 1.00 \\
R113 & 1.30 & Kerosene & 0.488 \\
R114 & 1.24 & & \\
\hline
\end{tabular}



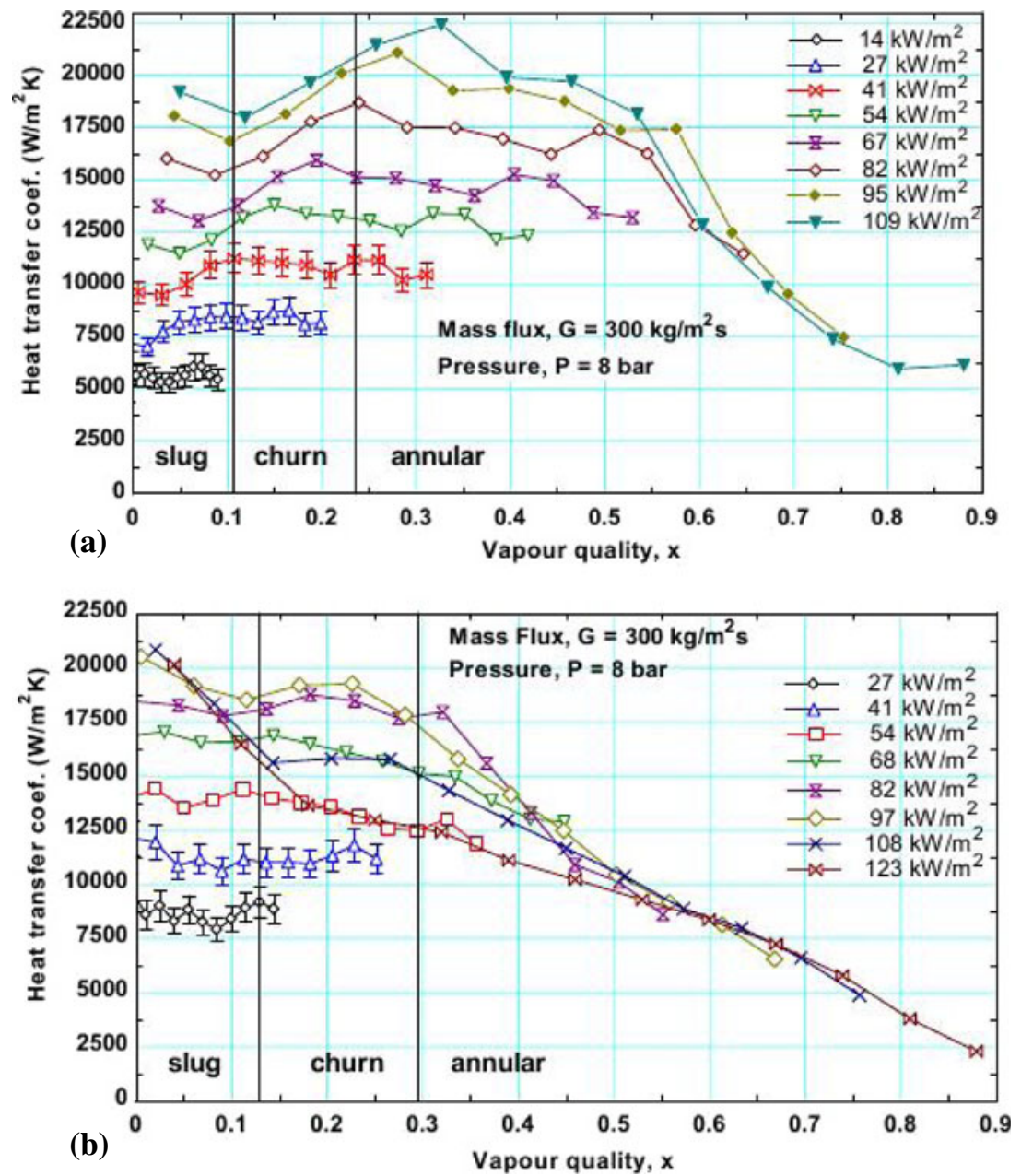

Figure 11. (a) Local heat transfer coefficient as a function of vapour quality at different heat fluxes (a) $\mathrm{d}-4.26 \mathrm{~mm}$. (b) Local heat transfer coefficient as a function of vapour quality at different heat fluxes (b) $\mathrm{d}-2.01 \mathrm{~mm}$.

\subsection{Critical heat flux $(\mathrm{CHF})$}

Critical heat flux (CHF) in flow boiling is the heat flux that results in a sudden rise in the wall temperature. There are basically two classes of CHF situations, namely departure from nucleate boiling (DNB) and dry-out (DO). DNB occurs at very low qualities or even under sub-cooled liquid conditions; here the vapour generation rate is higher than the rate of vapour evaporation by the flowing liquid. This leads to an accumulation of vapour at the generation site and prevents liquid from contacting the surface. The vapour therefore gets superheated and the wall temperature rises suddenly due to the relatively poor heat transfer characteristics of vapour. In contrast to DNB, dry-out occurs at high qualities and is a result of the gradual disappearance of the liquid 
film adjacent to the wall as a result of both entrainment and evaporation. Dry-out occurs in annular flow and a significant amount of liquid may still be flowing in the form of droplets entrained by the vapour.

The terms critical heat flux (CHF) and dry-out are both used to describe a situation when the heated surfaces are no longer wetted by the liquid. Strictly speaking, the way in which this situation is reached determines whether it should be termed critical heat flux or dry-out. Critical heat flux could appear at any vapour fraction and represents the upper limit of the heat flux where liquid is still in contact with the surface. Dry-out appears at high vapour fraction, independent of heat flux, when there is not sufficient liquid left to fully wet the walls of the channel. At dry-out condition, the wall temperature starts increasing due to the heat transfer deterioration.

CHF refers to the heat transfer limit causing a sudden decrease in the heat transfer coefficient and possible catastrophic failure of a device in which evaporation or boiling is occurring. The ability to predict the CHF is therefore of vital importance to the safety of flow boiling system.

Critical heat flux has been studied extensively over the past several decades. Authoritative reviews on the subject may be found in Tong et al (1997), Hewitt \& Hall-Taylor (1970) and Katto \& Ohno (1984).

Flow boiling CHF can be classified as either sub-cooled CHF or saturated CHF. For the sub-cooled CHF, several theories have been proposed to explain its mechanism: intense boiling causes the boundary layer separation from the heated wall and the resulting stagnant liquid depletion (Kutateladze \& Leont 1966; Tong 1968), bubble crowding within the boundary layer inhibits liquid replenishment near the wall surface (Weisman \& Pei 1983), and dry-out of a liquid sub layer beneath vapour blankets causes the appreciable rise of local wall temperature (Lee \& Mudawar 1988; Vijayarangan et al 2006). For the saturated CHF, the liquid film dryout near the channel outlet is widely regarded as the trigger mechanism (Hewitt \& Hall-Taylor 1970). At low flow rates in small-diameter tubes this type of CHF may be prone to occur due to the thinner liquid film thickness.

As the transport process behind the flow boiling CHF is extremely complex, CHF prediction relies heavily on empirical correlations derived from experimental CHF databases. There are many correlations (Maqbool et al 2012) in the literature that apply exclusively to water. Some of them are reported in table 8 . Few of them are compared using water and $n$-pentane as working fluid respectively (see figures $12 \mathrm{a}-\mathrm{b}$ ). It is observed that there exists a strong dependence of CHF on mass flux, heated length and inner diameter.

Therefore, the applicability of existing CHF correlations to small-diameter channels should be carefully examined in detail. Although many analytical and experimental studies related to flow boiling CHF in small-diameter channels have been performed in the past decades, a reliable CHF correlation applicable to a wide range of parameters for small-diameter channels has not been developed yet.

Summary of investigations on boiling in mini and microchannels regarding heat transfer coefficient, pressure drop and flow regimes, CHF was done and reported in table 9.

\subsection{Film thickness}

The development of techniques to measure liquid film thickness has been an important topic in the area of two-phase flow and many methods have been developed for it. The methods can be classified into four groups according to their measurement principles: 1) optical, 2) acoustic, 3) radiological and 4) electrical methods. In optical methods various optical devices such as high speed cameras and lasers are used for detecting an interface (Coney et al 1989; Ursenbacher et al 2004), total internal reflection of light (Yu et al 1996), fluorescence intensity (Schubring et al 
Table 8. Critical heat flux correlations.

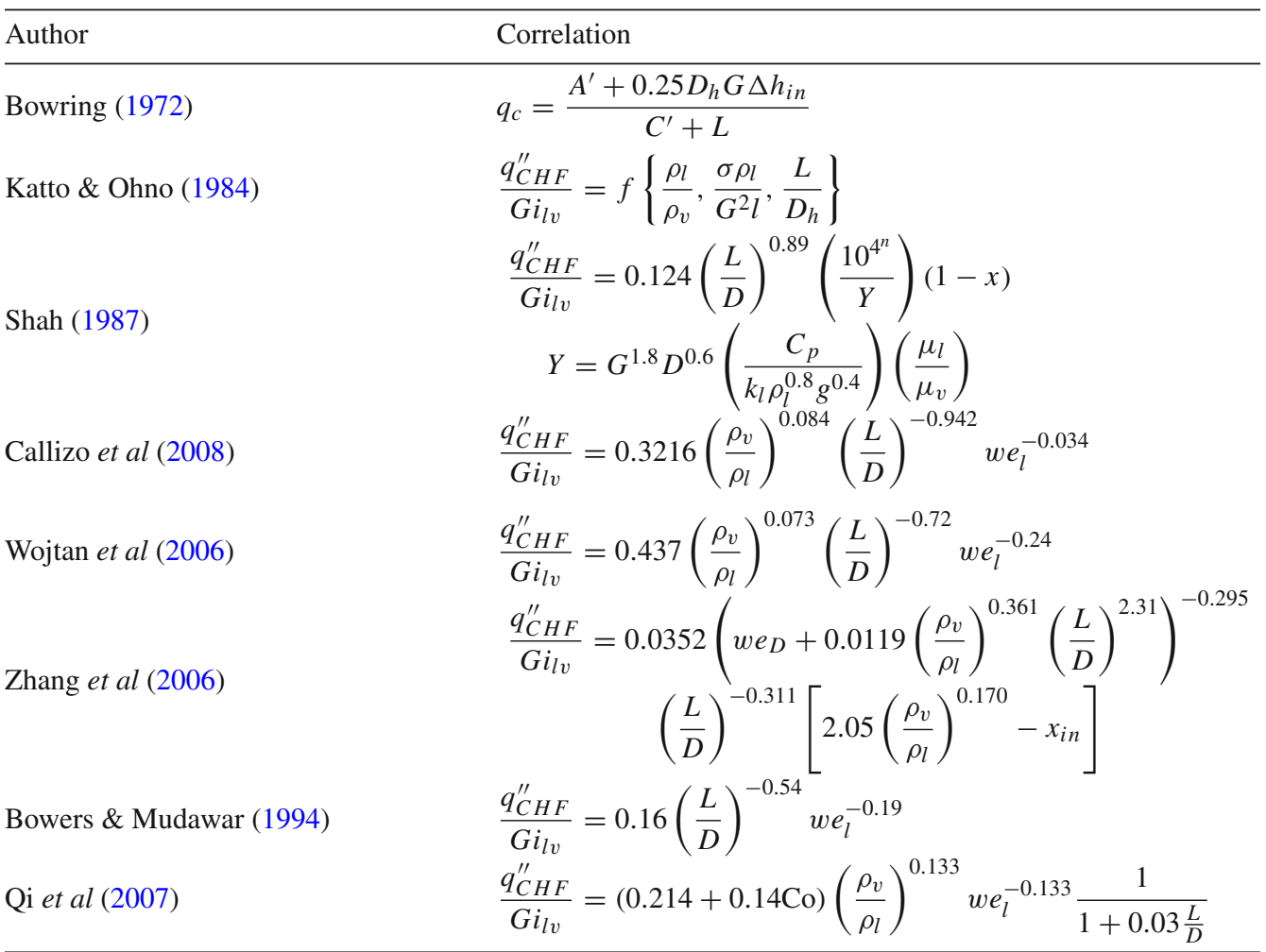

2010) and so on. Acoustic methods are based on the fact that ultrasonic waves are reflected at the gas-liquid interface and the time interval between the emitted and the reflected signal is converted into the film thickness ( $\mathrm{Lu}$ et al 1993; Pederson et al 2000). Radiological approaches use radiation, such as X-ray, gamma-ray, and neutrons. In radiological methods, the different attenuation characteristics in gas and liquid are used to measure the liquid film thickness (Stahl \& Rohr 2004; Saito et al 2005). Electrical methods are classified into two approaches: conductance and capacitance. The conductance (or the capacitance) between electrodes placed on the inner surface of the pipe is dependent on the conductivity (or the dielectric constant) of each phase and its morphology. The conductance method is cheaper than the other methods: it is non-intrusive and does not disturb flows. In addition, the response to the change of the liquid film thickness is very fast. To measure liquid film thickness, Coney (1973) proposed a conductance probe composed of two parallel electrodes with unequal widths and separated by an insulator and developed a theoretical model to analyze the relationship between the conductance and the liquid film thickness. Fukano (1998) suggested in-line and concentric ring-type probes and successfully applied them to the liquid film thickness measurement in a rectangular test section. Conte (2003) and Geraci et al (2007) proposed flush-mounted pin probes. The method is used for very thin films, typically up to $2 \mathrm{~mm}$ (pipe diameter $=127 \mathrm{~mm}$ ). However, their work dealt with measuring thicker films up to $11 \mathrm{~mm}$ (pipe diameter $=80 \mathrm{~mm}$ ). More recently, Liu et al (2007) used Electrical Capacitance Tomography (ECT) based image reconstruction to extract the liquid film thickness information. 

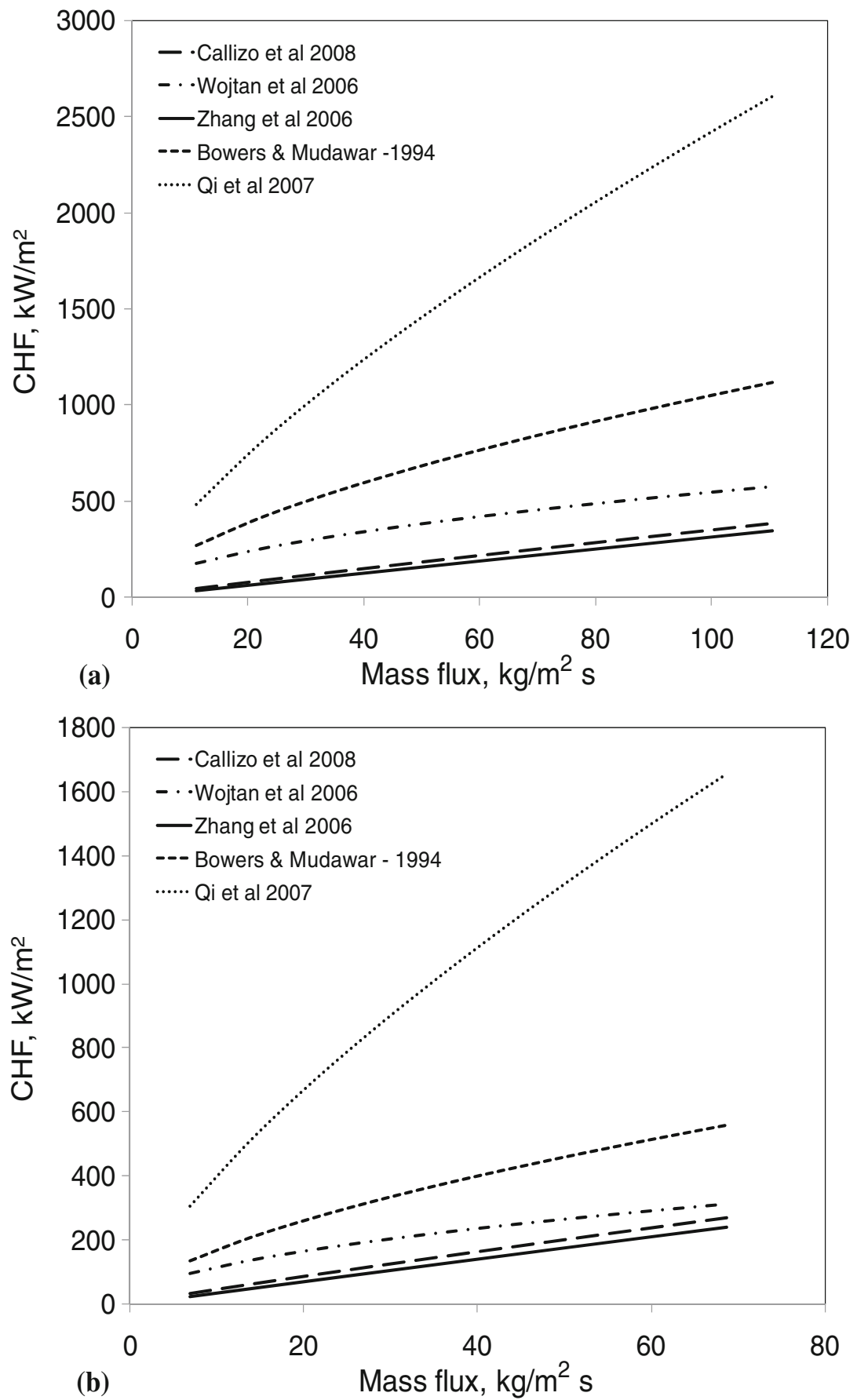

Figure 12. (a) Comparison of CHF correlation using water as working fluid. (b) Comparison of CHF correlation using $n$-Pentane as working fluid. 
Two-phase flow boiling in small channels

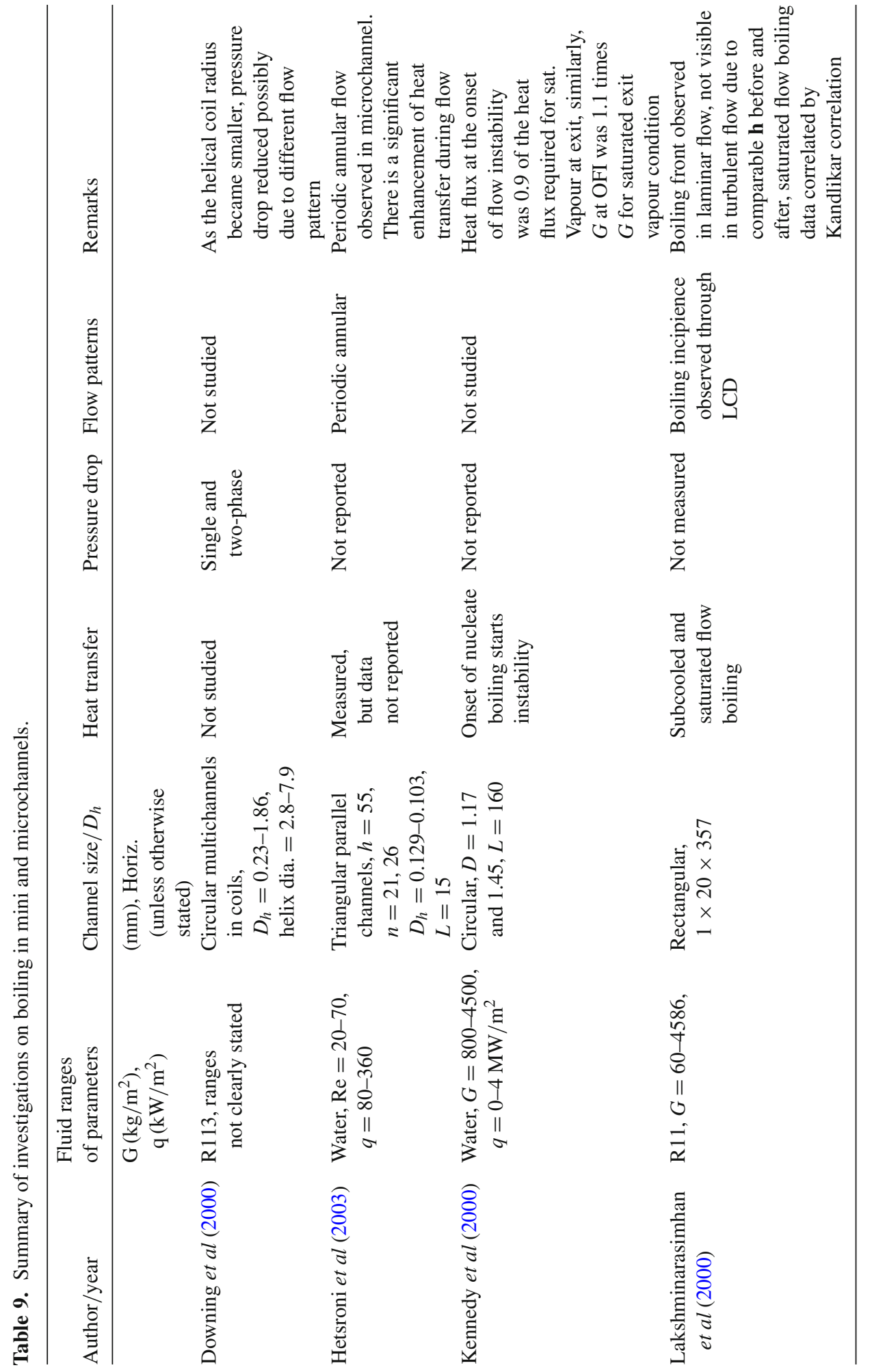




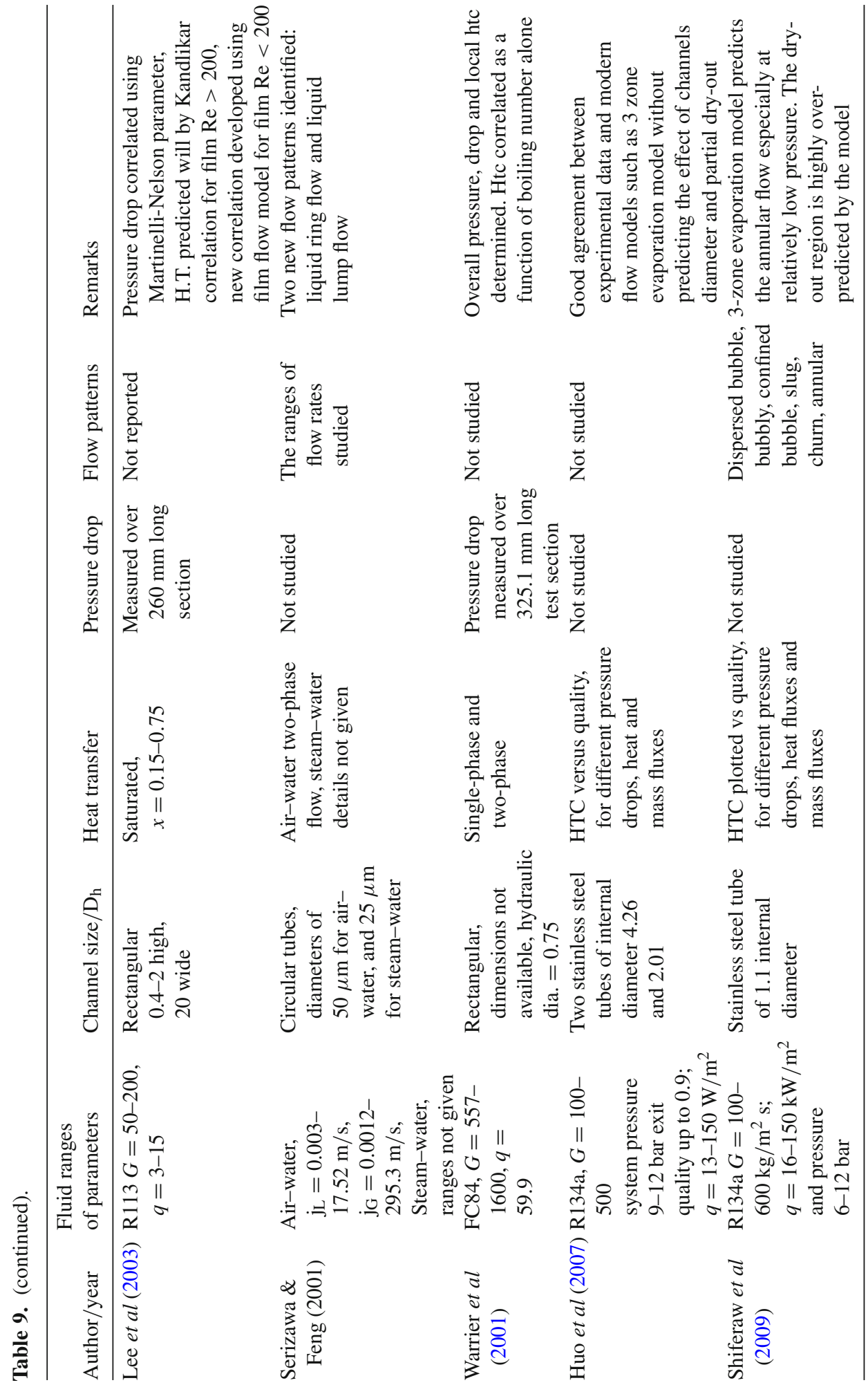




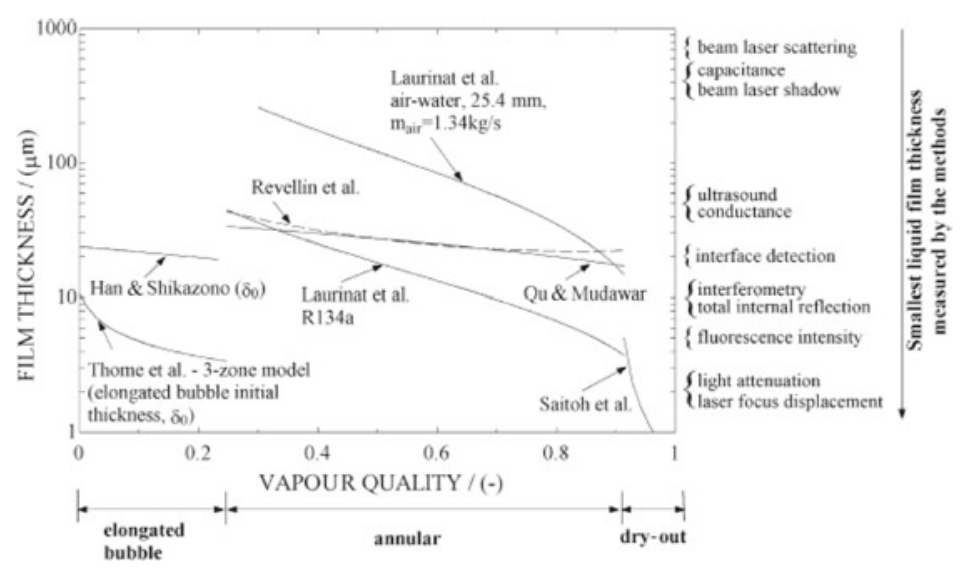

Figure 13. Comparison between the smallest film thickness measured by different methods and some estimated film thicknesses according to models from the literature. R134a, diameter of $770 \mathrm{~lm}$, mass velocity of $467 \mathrm{~kg} / \mathrm{m}^{2} \mathrm{~s}$, heat flux of $10 \mathrm{~kW} / \mathrm{m}^{2}$ and saturation temperature of $100^{\circ} \mathrm{C}$.

Recently, it is reported that liquid film thickness provides information to define the small to micro-scale transition in two-phase flow using high speed imaging (Ong \& Thome 2010). Attempt was also made by Revellin \& Thome (2007) for collecting experimental data for 0.5 to $0.8 \mathrm{~mm}$ channel size with two refrigerants (R134a and R245 fa). They developed a model and compared their results with the experimental data of Tibiriçá \& Ribatski (2009). It was observed that the model failed in predicting when its estimated film thickness was used to calculate the local heat transfer coefficient. Tibiriçá et al (2010) also carried out experiments in order to measure film thickness in microchannels. It is also mentioned that once the local liquid film thickness is known, it becomes easier to estimate the superficial void fraction.

Despite its importance, only few authors have addressed the issue of measuring the liquid film thickness in micro-scale two-phase flow system. This is mainly because the main challenge in measurement of film thickness is related to the small dimensions involved, and the inherent difficulties in developing non-intrusive transducers at these scales. Moreover, the small film thickness requires a non-invasive measuring method to avoid disturbance to the flow. As the experimental data reported is limited, measurement of film thickness in a small channel diameter looks to be a promising area for further research. The comparison between different film thickness measurement methods and model based estimation of film thicknesses from the literature is presented in figure 13.

\subsection{Modelling of boiling in small channels}

There are a considerable number of heat transfer correlations that can be used for modelling of flow boiling in different channels. Comprehensive review on this topic has been carried out by Thome (1996). A paramount difficulty in development of correlations for flow boiling at small mass flow rates and moderate heat fluxes (refrigeration, air-conditioning) or alternatively at large mass flow rates and high heat fluxes (power engineering). Capturing all these trends with only single correlation is a very difficult task. 
Kattan et al (1998a) argues that the models based on distinguishing between flow regimes should be seriously considered for general use. Wojtan et al (2005) postulated models for stratified wavy and mist flow regimes. These models are very promising; however they fall under the class of the regime-dependent models. They require knowledge of the particular flow regime, as well as the proportion of liquid and gaseous phase in the flow. For that reason such model is difficult to be applied in engineering practice, as it requires prior knowledge of the flow regimes and conditions. Heat transfer issues in small diameter channels received attention in numerous papers, e.g., Bergles et al (2003), Kandlikar (2001) etc.

One of the major difficulties in modelling two-phase flow is the determination of the geometry of the flow field which can adopt several configurations commonly referred to as flow pattern or flow regimes. Significant engineering design values such as heat transfer and pressure drop are closely related to this distribution, the calculation of two-phase flow pattern by means of CFD modelling can be very useful (Schepper et al 2008). These flow calculations are computationally very demanding. They made use of existing CFD code for modelling of two-phase flow in horizontal tubes for air-water and liquid-vapour flow. For simulations the Eulerian-Eulerian as well as VOF model approach is chosen. In the VOF model, the Eulerian framework is taken for both the phases combined with reformulation of interface forces on volumetric basis. Simulation work involves 3D simulations of horizontal flow regimes observed in two-phase liquid-vapour system. The simulation results for the different horizontal flow regimes can be found in figure 14. It can be concluded that the VOF model in combination with PLIC interface reconstruction method implemented in existing code predicts the expected flow regime accurately.

Similarly, Anglart \& Caraghiaur (2011) developed two-phase annular mist flows with evaporating liquid films. This type of flow exists in boiling channels prior to onset of dry-out. Annular-mist flows have a very complex structure since they contain liquid and vapour, both as the continuous and the dispersed phase. Due to this feature, both the Eulerian-Eulerian as well as the Eulerian-Lagrangian approaches were often used to model such flows. The two approaches, with pertinent conservation equations and closure relationships were used by Anglart \& Caraghiaur (2011) for modelling annular-mist flows.

In the CFD code, for example in Fluent software, the two-phase flow phenomenon can be modeled in several ways. The two-phase flow models used in Fluent are Euler-Euler models.

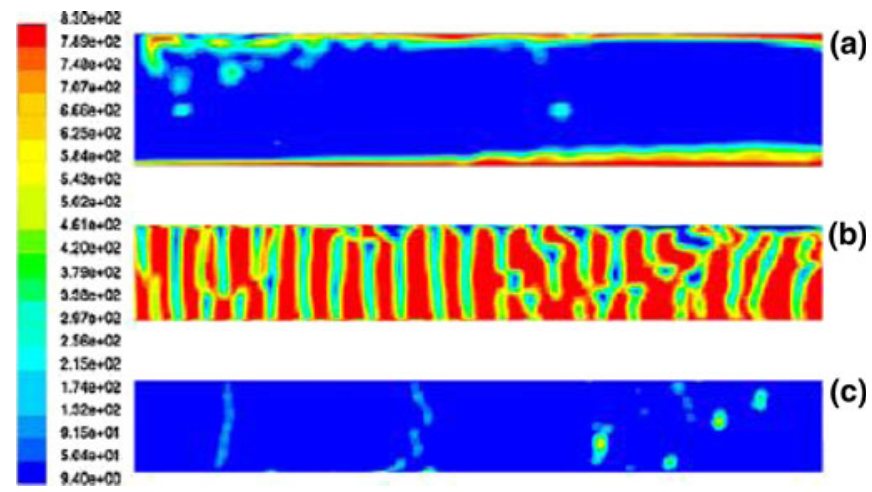

Figure 14. Contours of mixture density for liquid-vapour gasoil flow. (a) Annular flow, (b) bubbly flow, (c) dispersed flow (Schepper et al 2008). 
These models treat the different phases as interpenetrating continua. Since the volume of a phase cannot be occupied by the other phases, the concept of phase's volume fraction is introduced. The conservation equations for each phase are derived to obtain a set of equations, which have a similar structure for all phases. For the higher void fraction cases, such as slug flow it is recommended to use the VOF model (Dostal et al 2008). The slug flow is the most important flow regime in two-phase flow system primarily because of numerous industrial and practical applications. Taha \& Cui (2006) studied CFD modelling of slug flow in vertical tubes. They have used Fluent software to simulate the motion of single Taylor bubble rising in motionless or flowing liquid through a vertical tube using VOF approach. A fully developed velocity profile is imposed at the inlet and relative movement between the liquid and wall generates a velocity profile as shown in figure $15 \mathrm{a}$. The geometric reconstruction scheme that is based on piece linear interface calculation method (PLIC) is applied to reconstruct the bubble free interface. 3D simulation of bubble was conducted to capture the $3 \mathrm{D}$ nature of the flow. The unstable and transient nature of the flow surrounding the bubble from laminar to turbulent, produces significant modification to the bubble profile and stability as shown in figure $15 \mathrm{~b}$. There bubble tail oscillates and small bubble can be seen shed at the bubble rear.

Similarly, numerical simulation by CFD using the volume of fluid (VOF) method (Hirt \& Nicholos 1981) has been applied in modelling two-phase bubbly flow since 1980s. The advantages of the VOF method may lie in its simple concept, reasonable accuracy and is relatively easy to implement. Thus it could be used to simulate complex phenomena such as interface

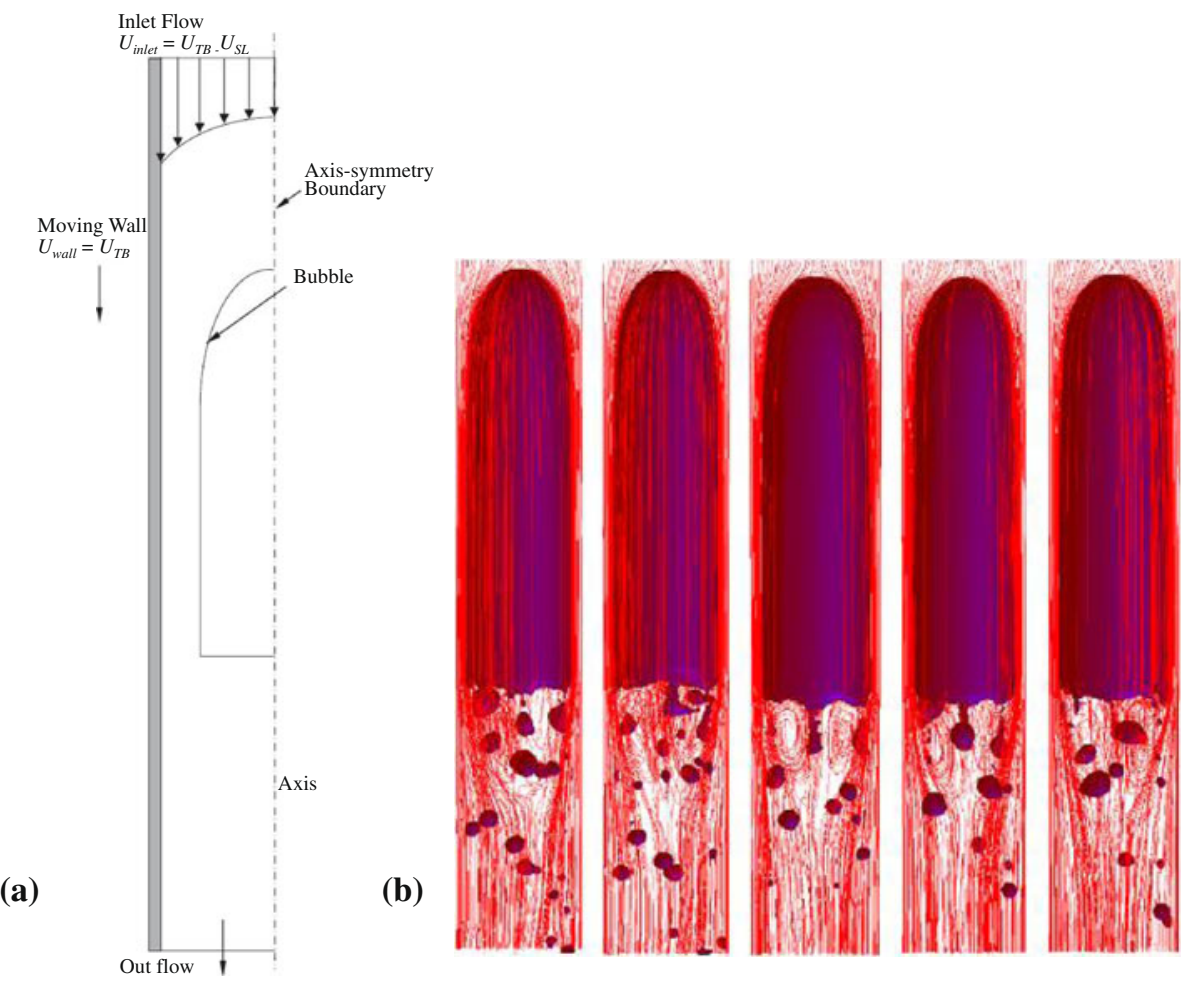

Figure 15. (a) Initial BC for Taylor bubble rising in vertical pipe (Taha \& Cui 2006). (b) Progression of wake flow pattern behind Taylor bubble rising through a stagnant liquid. 
Two-phase flow boiling in small channels

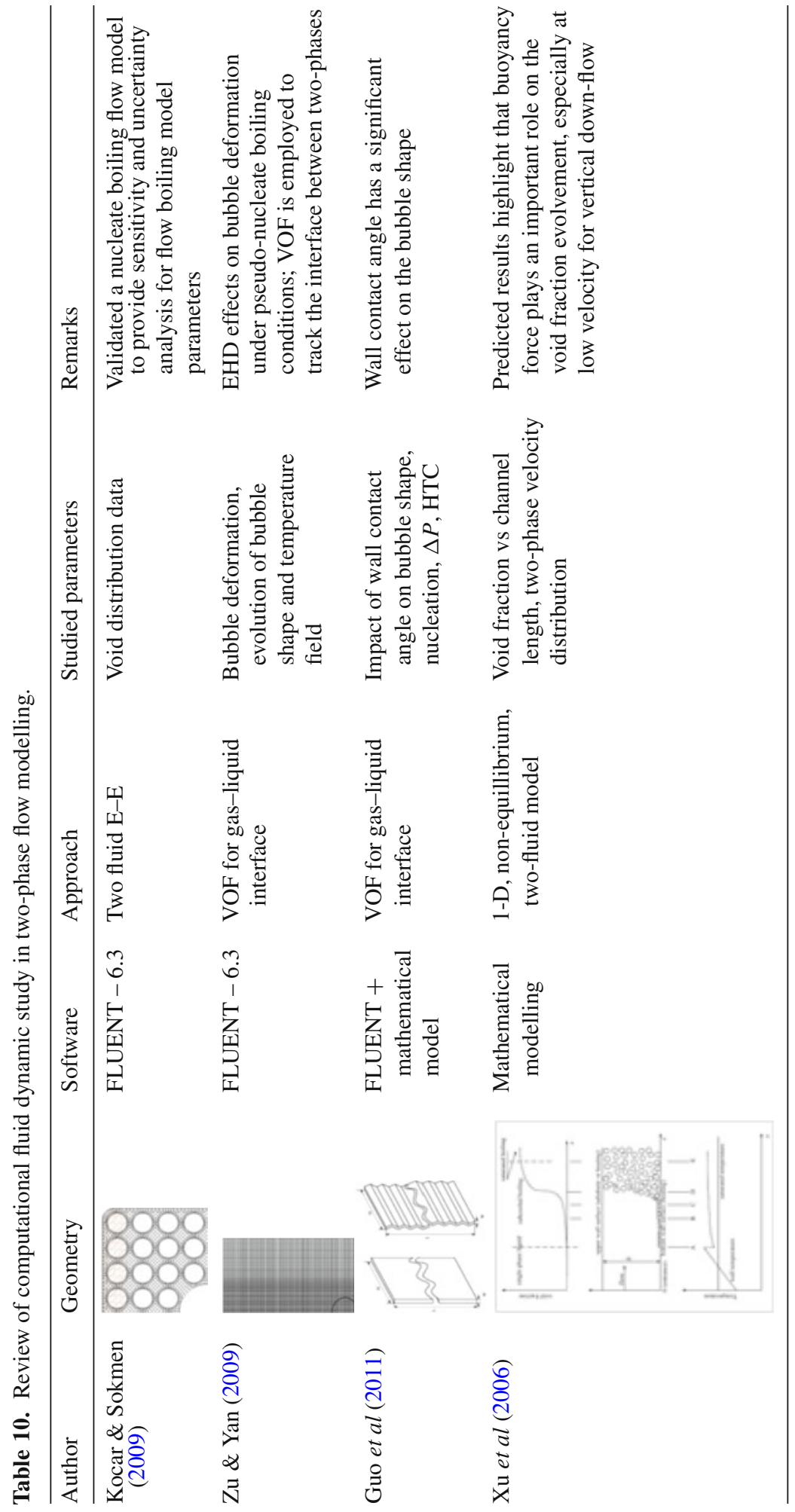




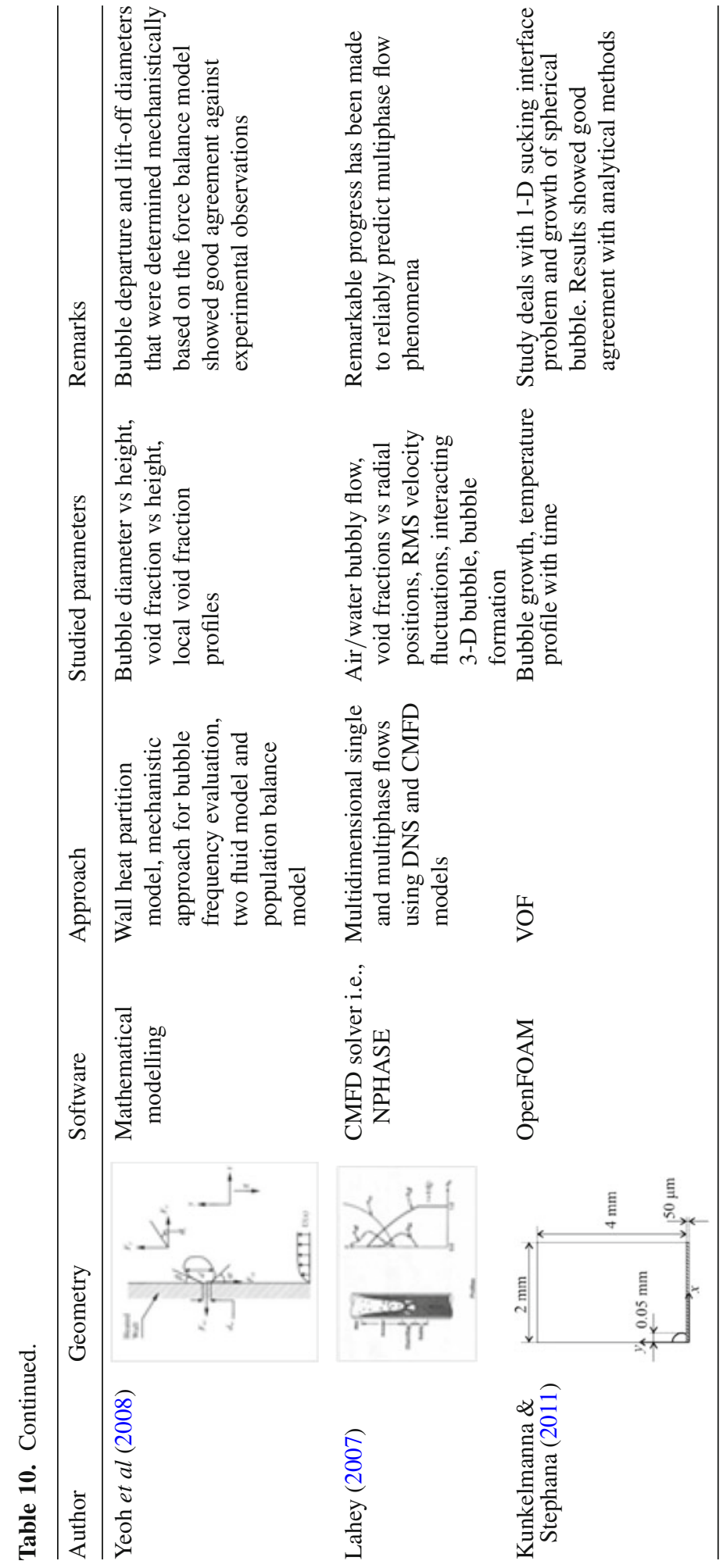


breakup and coalescence etc. (Gopala \& van Wachem 2008). However, the 3-D interface reconstruction in VOF is numerically prohibitive and therefore may result in some uncertainties on the interface curvature and thus on the surface tension forces. Son \& Dhir (1999) developed a twodimensional numerical model of growth and departure of single vapour bubbles during nucleate pool boiling. In the model, the level set technique was used for tracking the liquid vapour interface. The model was then extended by Mukherjee \& Kandlikar (2005) to 3-D cases to simulate the growth of a bubble from a nucleation site on the side wall of a rectangular channel to confinement. The channel was restricted in length and the interaction between pressure changes and evaporation was not taken into account. The main drawback of the level set methods is that its numerical computation can generate mass loss in under-resolved regions (Sussman et al 1994). Yan \& Zu $(2007,2008)$ developed their lattice Boltzmann method (LBM) with the capability of modelling of two-phase flow of fluids with large liquid-gas density ratio, and fluid wall interactions to simulate bubbles behaviour in mini-/microchannels. Despite its numerical advantages, the method is time consuming and generally difficult. Various studies on this are summarized in table 10 which covers different geometries, modelling approaches and key parameters for two-phase flow boiling.

\section{Summary, conclusions and path forward}

A review on flow boiling in small channels is presented. It was observed that flow boiling has been studied extensively for last few decades. However issues concerning flow boiling heat transfer and two-phase flow transport phenomena in small diameter channels are quite different from these encountered in conventional large channels. Published literature on this is summarized in this paper. It was highlighted that the channel size classification is merely a guide to help us identify the channel size ranges in various applications. The operating parameters, such as system pressure, and fluid properties, such as density, viscosity, and surface tension, have a major influence on prevailing flow characteristics.

Identification of flow regimes in a heated section is very difficult and complicated task. This is because spatially varying flow regime ranging from bubbly flow to mist flow occur in such a heated section. Relatively limited research have been carried out so far on flow boiling patterns and heat transfer in small diameter tubes for different fluids. It was also observed that different experimental conditions were used (such as different temperature, mass flux, heat flux and pressure) by different investigators, which makes it difficult to compare results directly. In addition, the identification of flow patterns may be greatly affected by the observer's subjectivity and the experimental technique employed.

In two-phase flow boiling, continuously varying flow regimes also make development of generalized correlations for frictional pressure drop and effective heat transfer coefficient rather complex. The prediction of critical heat flux (CHF) also relies heavily on empirical correlations derived from experimental data. Available experimental and modelling studies on flow boiling in small channels are critically reviewed in this work. Efforts have also been made to evolve some broad guideline for the future research in this important area. Some of the key conclusions drawn from this review can be outlined as:

- Classification of small diameter channels into mini and micro (where surface phenomena dominates) channels is not clearly established in the literature. Further work is necessary to clarify changes in regimes of heat transfer and boiling over intermediate (between microand mini) range of diameters of small channels. 
- Flow visualization and transition criteria of two-phase flow in small channels should relate to flow boiling heat transfer mechanisms which intrinsically relate to flow patterns. The continuous variation in flow regimes along the boiler tubes complicates development of generalized correlations for effective pressure drop and heat transfer. Further work on relating the observed overall pressure drop and heat transfer data to underlying spatio-temporal scales and fluid dynamics is needed to enhance appropriate interpretation of reported experimental data and therefore subsequent applications.

- The accurate prediction of void fraction in vertical channels is of immense importance in determining the two-phase pressure drop. Therefore, a few void fraction correlations are reported in table 6 and compared in figures $7 \mathrm{a}-\mathrm{b}$. It was observed that Lockhart \& Martinelli (1949) correlation is most useful for the design calculations.

- It is observed that a strong dependence of CHF on mass flux, heated length and inner diameter. Reported CHF correlations tried to compare using water and $n$-pentane as working fluid. It was observed that CHF predicted by Qi et al (2007) correlation was maximum at particular mass flux as compared to other reported correlations.

- A systematic and consistent experimental data base on flow boiling characteristics of a small-channel is needed. The lack of such data is also hindering further development in computational modelling.

Suggestions for further work

- It is important that flow regime maps be first developed based on simultaneous high-speed visualization and local heat transfer and pressure drop measurements in carefully characterized experimental set-ups. Such a broad database would then allow the development and validation of models which are based on the prevailing flow regimes.

- A generalized effective pressure drop and heat transfer model should be targeted by incorporating various flow regimes, heat transfer mechanisms, channel sizes, component compositions, instabilities and so on.

- The film thickness measurement requires a non-invasive measuring method to avoid disturbance to the flow. Hence, it is observed that this is a promising area for further research where very limited information is available on the measurement of film thickness. This may also shed light on dry-out phenomena and related instabilities.

- Better computational models and modelling approaches are needed to develop reliable, accurate and yet tractable, numerical simulations of boiling flows. Accurate prediction of bubble generation, growth and departure from wall is still difficult and remains a challenge. Detailed experimental data for validation and possibly multi-scale modelling may provide a way forward.

It is envisaged that a systematic research on two-phase flow and flow boiling in small channels will bring advancement of knowledge and meet the practical requirements in various applications. This review may provide a starting point for this long and arduous journey.

\section{Nomenclature}

$\mathrm{A}_{\mathrm{S}}$ heat transfer surface area, $\mathrm{m}^{2}$

Bo boiling number

Co convection number $\left(\rho_{G} / \rho_{L}\right)^{0.5}((1-x) / x)^{0.8}$

$D_{h}$ tube diameter, $\mathrm{mm}$ 
$f$ fanning friction factor

$F_{F l}$ fluid-surface parameter

Fr Froude number

$G$ mass flux, $\mathrm{kg} / \mathrm{m}^{2} \mathrm{~s}$

$h_{L O}$ all-liquid flow single-phase heat transfer coefficient, $\mathrm{W} / \mathrm{m}^{2}{ }^{\circ} \mathrm{C}$

$h_{T P}$ two-phase heat transfer coefficient, $\mathrm{W} / \mathrm{m}^{2}{ }^{\circ} \mathrm{C}$

$i_{L G}$ specific enthalpy, $\mathrm{J} / \mathrm{kg}$

$L$ length of tube, $\mathrm{m}$

$\mathrm{Nu}$ Nusselt number

Pavg test section average pressure, $\mathrm{kPa}$

$q$ heat flux, $\mathrm{W} / \mathrm{m}^{2}$

$\operatorname{Re}_{L o}$ Reynolds number

$T$ temperature, ${ }^{\circ} \mathrm{C}$

$X$ vapour quality

$d$ hydraulic diameter $=4$ (cross-sectional area/perimeter of tube), $\mathrm{m}$

$F$ Enhancement factor, or Chen's Reynolds number factor

$g$ acceleration due to gravity, $\mathrm{m} / \mathrm{s}^{2}$

$k$ liquid thermal conductivity, $\mathrm{W} / \mathrm{mK}$

$M$ molecular mass

$N$ number of data points

$\delta$ thickness of film

$\mathrm{p} r$ reduced pressure

$S$ suppression factor

$(1-x)$ dryness fraction

$\Delta P_{\text {static }}$ static pressure drop

$\Delta P_{\text {momentum }}$ momentum pressure drop

$\Delta P_{\text {friction }}$ frictional pressure drop

$\rho_{H}$ homogenous density

$H$ vertical height

$\theta$ angle with respect to horizontal

$\rho_{L}$ liquid density

$\rho_{G}$ gas density

$\varepsilon_{H}$ void fraction

$V_{V} / V_{L}$ velocity ratio or slip ratio

$x$ vapour quality

$f_{t p}$ two-phase friction factor

$\dot{m}$ mass flow rate, $\mathrm{kg} / \mathrm{s}$

$D_{i}$ inner diameter, $\mathrm{m}$

$\rho_{t p}$ two-phase density

$\mu_{t p}$ quality averaged viscosity

$\Delta P_{L}$ liquid phase flow pressure drop

$\Phi_{f r}$ Friedel two-phase multiplier

$\Phi_{L t t}$ two-phase multiplier for liquid phase

$\Phi_{G t t}$ two-phase multiplier for gas phase

$\Phi_{g d}$ Gronneurd correlation two-phase multiplier

$\Phi_{c h}$ Chishlom two-phase multiplier

$\Phi_{B f}$ bankoff two-phase multiplier 


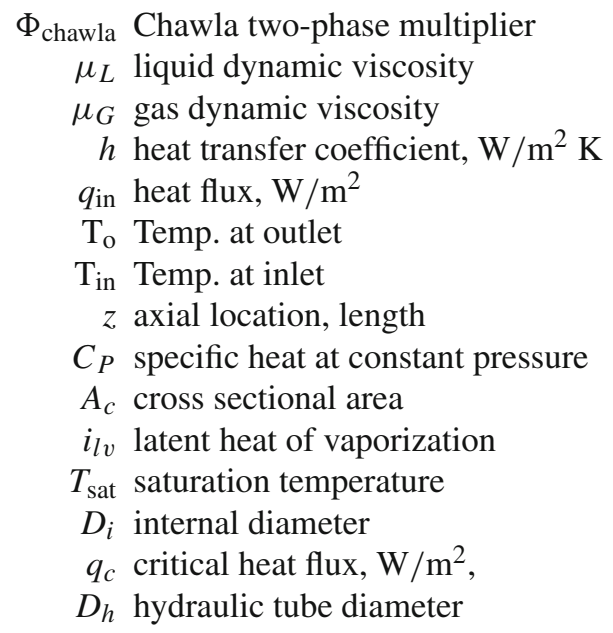

\section{References}

Akbar M K, Plummer D A and Ghiaasiaan S M 2003 On gas-liquid two-phase flow regimes in microchannels. Int. J. Multiphase Flow 29: 855-865

Anglart H and Caraghiaur D 2011 CFD modelling of boiling annular-mist flow for dryout investigations. Multiph. Sci. Technol. 23(2): 223-251

Armand A A 1946 The resistance during the movement of a two-phase system in horizontal pipes. Izv. Vse. Tepl. Inst. 1: 16-23

Baker O 1954 Simultaneous flow of oil and gas. Oil Gas J. 53: 185

Balasubramanian P and Kandlikar S 2005 Experimental study of flow patterns, pressure drop, and flow instabilities in parallel rectangular minichannels. Heat Trans. Eng. 26(3): 20-27

Bankoff S G 1960 A variable density single-fluid model for two-phase flow with particular reference to steam-water flow. J. Heat Transfer 11: 265-72

Barnea D 1987 A unified model for predicting flow-pattern transitions for the whole range of pipe inclinations. Int. J. Multiphase Flow 13(1): 1-12

Barnea D, Luninski Y and Taitel Y 1983 Flow pattern in horizontal and vertical two-phase flow in small diameter pipes. Can. J. Chem. Eng. 61(5): 617-620

Bergles A E, Lienhard J H, Kendall G E and Griffith P 2003 Boiling and evaporation in small diameter channels. Heat Trans. Eng. 24: 18-40

Bowers M B and Mudawar I 1994 High flow boiling in low flow rate, low pressure drop mini-channel and micro-channel heat sinks. Int. J. Heat Mass Transfer 37: 321-332

Bowring R W 1972 A simple but accurate round tube uniform heat flux, dryout correlation over the pressure range 0.7-17 MN/m2 (100-2500 psia), AEEW-R 789, United Kingdom Atomic Energy Authority

Brauner N and Moalem-Maron D 1992 Identification of the range of small diameter conduits regarding two-phase flow pattern transitions. Int. Commun. Heat Mass Transfer 19: 29-39

Bruno A and Bontemps A 2005 Vertical flow boiling of refrigerant R134a in small channels. Int. J. Heat Fluid Flow 26: 296-306

Callizo C M, Ali R and Palm B 2008 Dryout incipience and critical heat flux in saturated flow boiling of refrigerants in a vertical uniformly heated micro channels, In: Proc. of the Sixth Int. ASME Conf. on Nano, Micro and Mini channels, ICNMM, Darmstadt, Germany, 2008

Chawla J M 1967 Wärmeü bergang und Druckabfall in waagerechten Rohren bei der Strömung von verdampfenden Kä ltemitteln. VDI-Forschungsh, 523 Lg1-Lg2 
Chen J C 1963 A correlation for boiling heat transfer to saturated fluid in convective flow, ASME Paper, 63-HT-34, 1-11

Chen J J J 1986 A further examination of void-fraction in annular two-phase flow. Int. J. Heat Mass Transfer 29: $1760-1763$

Chen T and Garimella S V 2006 Measurement and high speed visualization of flow boiling of dielectric fluid in a silicon micro channel heat sink. Int. J. Multiphase Flow. 32: 957-971

Cheng L and Mewes D 2006 Review of two-phase flow and flow boiling of mixtures in small and mini channels. Int. J. Multiphase Flow 32: 183-207

Chisholm D 1973 Pressure gradients due to friction during the flow of evaporating two-phase mixtures in smooth tubes and channels. Int. J. Heat Mass Transfer 16: 347-358

Chisholm D 1983 Two-phase flow in pipelines and heat exchangers, George Godwin in association with The Institution of Chemical Engineers, London

Chung P M-Y and Kawaji M 2004 The effect of channel diameter on adiabatic two-phase flow characteristics in microchannels. Int. J. Multiphase Flow 30: 735-761

Collier J G and Thome J R 1994 Convective Boiling and Condensation, New York: Oxford University Press

Coney J E R, El-Shafei E A M and Sheppard C G W 1989 A dual laser beam method for wavy film thickness measurement. Optics Lasers Engg. 11: 1-14

Coney M W E 1973 The theory and application of conductance probes for the measurement of liquid film thickness in two-phase flow. J. Phys. E: Sci. Instrument 6: 903-910

Conte G 2003 Film thickness variation about T-junction. Int. J. Multiphase Flow 29: 305-328

Cooper M G 1984 Saturated nucleate pool boiling - A simple correlation, 1st UK National Heat Transfer Conference, IChemE Symposium Series No 86, 2: $785 \pm 93$ (IChemE, Rugby)

Damianides C and Westwater J 1988 Two-phase flow patterns in a compact heat exchanger and in small tubes, In: 2nd Proc. of the UK National Conf. on Heat Transfer, Glasglow, Mechanical Engineering Publications, September 1988, pp. 1257-1268

Dittus F W and Boelter L M K 1930 Heat transfer in automobile radiators of tubular type, Univ. California, Berkeley. Publ. Engrg. 2(13): 443-461

Dostal V, Zelenzy V and Zacha P 2008 Simulations of two phase flow in Fluent, ANSYS Konference, 16. ANSYS FEM Users 'Meeting \& 14. ANSYS CFD Users' Meeting Luhačovice 5. - 7. listopadu 2008

Downing R S, Meinecke J and Kojasoy G 2000 The effects of curvature on pressure drop for single and twophase flow in miniature channels, Proc. of NHTC2000: $34^{\text {th }}$ National Heat Transfer Conf., Pittsburgh, PA, August 20-22, 2000, Paper No. NHTC2000-12100

Friedel L 1979 Improved friction pressure drop correlations for horizontal and vertical two-phase pipe flow, In: Proc. of the European Two-Phase Flow Group Meeting, Ispra, Italy

Fukano T 1998 Measurement of time varying thickness of liquid film flowing with high speed gas flow by constant electric current method. Nucl. Eng. Des. 184: 363-377

Geraci G, Azzopardi B J and Van Maanen H R E 2007 Effect of inclination on circumferential film thickness variation in annular gas-liquid flow. Chem. Eng. Sci. 62: 3032-3042

Godbole P V, Tang C C and Ghajar A J 2011 Comparison of void fraction correlations for different flow patterns in upward vertical two-phase flow. Heat Trans. Eng. 32(10): 843-860

Gopala V R and van Wachem B G M 2008 Volume of fluid methods for immiscible- fluid and free surface flows. Chem. Eng. J. 141: 204-221

Gronnerud R 1979 Investigation of liquid hold-up, flow-resistance and heat transfer in circulation type evaporators, part IV: two-phase flow resistance in boiling refrigerants. Annexe 1972-1, Bull. de l'Inst. du Froid

Gungor K E and Winterton R H S A 1986 A general correlation for flow boiling in tubes and annuli. Int. J. Heat Mass Transfer 29: 351-358

Guo L, Zhang S and Cheng L 2011 Study on characteristics of vapour-liquid two-phase flow in minichannels. Nucl. Eng. Des. 241: 4158-4164

Hamersma P J and Hart J 1987 A pressure drop correlation for gas/liquid pipe flow with a small liquid holdup. Chem. Eng. Sci. 42: 1187-1196 
Harirchian T and Garimella S V 2010 Comprehensive flow regime map for microchannel flow boiling with quantitative transition criteria. Int. J. Heat and Mass Transfer 53: 2694-2702

Hetsroni G, Gurevich M, Mosyak A, Pogrebnyak E, Rozenblit R and Yarin L P 2003 Boiling in capillary tubes. Int. J. Multiphase Flow 29: 1551-1563

Hewitt G F 2000 Fluid Mechanics Aspects of Two-Phase Flow, Chapter 9, Handbook of Boiling and Condensation, Eds. Kandlikar SG, Shoji M, Dhir VK, NY: Taylor and Francis

Hewitt G F 2007 Imperial College, London, England, Multiphase Flow in the Energy Industries. Internat. Global Energy Prize Scientific Conf:: June 7

Hewitt G H and Hall-Taylor N S 1970 Annular Two-phase Flow. NY: Pergamon Press

Hewitt G F and Roberts D N 1969 Study of Two-Phase Flow Patterns by simultaneous X-ray and flash photography. Atmoic Energy Research Establishment Harwell, AERE-M 2159, February 1969

Hirt C W and Nichols B D 1981 Volume of fluid method for the dynamics of free boundaries. J. of Comp. Phys. 39: 210-225

Hughmark G A 1965 Holdup and heat transfer in horizontal slug gas-liquid flow. Chem. Eng. Sci. 20: 10071010

Huo X, Chen L, Tian Y S and Karayiannis T G 2004 Flow boiling heat transfer and flow patterns in small tubes. Appl. Therm. Eng. 24: 1225-1239

Huo X, Tian Y S and Karayiannis T G 2007 R134a flow boiling heat transfer in small diameter tubes. In: Advances in Compact Heat Exchangers, R.T. Edwards, Inc., pp. 95-111 (Chapter 5)

Julia E, Ozar B, Jeong J, Hibiki T and Ishii M 2011 Flow regime development analysis in adiabatic upward two-phase flow in a vertical annulus. Int. J. Heat Fluid Flow 32(1): 164-175

Kandlikar S G 1990 A general correlation for saturated two-phase flow boiling heat transfer inside horizontal and vertical tubes. J. Heat Transfer 112: 219-228

Kandlikar S G 2001 Two-phase flow patterns, pressure drop and heat transfer during boiling in mini-channel and micro-channel flow passages of compact evaporators. In: Proc. of the Third Internat. Conf. on Compact Heat Exchangers and Enhancement Technology for the Process Industries, 1-6 July 2001, Davos. Begell House Inc., New York, pp. 319-334

Kandlikar S G 2002 Fundamental issues related to flow boiling in minchannels and microchannels. Exp. Thermal Fluid Sci. 26: 38-47

Kandlikar S G and Balasubramanian P 2004 An extension of the flow boiling correlation to transition, laminar, and deep laminar flows in minichannels and microchannels. Heat Trans. Eng. 25(3): 86-93

Kandlikar S G and Grande W J 2003 Evolution of microchannel flow passages-Thermohydraulic performance and fabrication technology. Heat Trans. Eng. 25(1): 3-17

Kandlikar S G and Steinke M E 2003 Predicting Heat Transfer During Flow Boiling in Minichannels and Microchannels. ASHRAE Annual Meeting, Chicago, January 24-29

Kandlikar S G, Steinke M E, Tian S and Campbell L A 2001 High-Speed Photographic Observation Of Flow Boiling Of Water In Parallel Mini-Channels, Paper presented at the ASME National Heat Transfer Conf., June, 2001, ASME

Karayiannis T G, Shiferaw D and Kenning D B R 2008 Saturated flow boiling in small to micro- diameter metallic tubes: experimental results and modelling. In: ECI Internat. Conf. on Heat Transfer and Fluid Flow in Microscale, Whistler, 21-26 September

Kattan N, Thome J R and Favrat D 1998a Flow boiling in horizontal tubes: Part 1 development of a diabatic two-phase flow pattern map. J. Heat Transfer 120: 140-147

Katto Y and Ohno H 1984 An improved version of the generalized correlation of critical heat flux for forced convective boiling in uniformly heated vertical tubes. Int. J. Heat Mass Transfer 27: 1641-1648

Kawahara A, Chung P M Y and Kawaji M 2002 Investigation of two-phase flow pattern, void fraction and pressure drop in a microchannel. Int. J. Multiphase Flow 28: 1411-1435

Kennedy J E, Roach Jr G M, Dowling M F, Abdel-Khalik S I, Ghiaasiaan S M, Jeter S M and Quereshi Z H 2000 The onset of flow instability in uniformly heated horizontal microchannels. ASME J. Heat Transfer 122: $118-125$ 
Kew P A and Cornwell K 1997 Correlations for the prediction of boiling heat transfer in small diameter channels. Appl. Thermal Eng. 17: 705-715

Kew P A and Cornwell K 2000 Flow boiling in compact heat exchangers, Handbook of Phase Change: Boiling and Condensation, Chapter 16.2, Taylor and Francis, pp. 412-427

Khodabandeh R and Palm B 2001 Heat transfer coefficient in the vertical narrow channels of the evaporator of an advanced thermosyphon loop, Proc. of Fourth Internat. Conf. on Multiphase Flow, ASME, New Orleans, May 27-June 1, 2001

Kim J M and Bang K H 2001 Evaporation heat transfer of refrigerant R- 22 in small diameter tubes, Proc. of Fourth Internat. Conf. on Multiphase Flow, ASME, New Orleans, May 27-June 1, 2001

Kocar C and Sokmen C S 2009 A CFD model of two-phase flow in BWRs with results of sensitivity and uncertainty analysis. Nuclear Engineering Design 239: 1839-1846

Koichi H, Hirokazu K, Masahiro S and Nobuaki N 2004 Critical heat fluxes of subcooled water flow boiling against inlet subcooling in short vertical tube. JSME Int. J., Series B 47(2): 306

Koo J M, Jiang L, Zhang L, Zhou L, Banerjee S S, Kenny T W, Santiago J G and Goodson K E 2001 Modelling of two-phase microchannel heat sinks for VLSI chips, Proc. of IEEE 14th Internat. MEMS conf., Interlaken, Switzerland, January 2001

Kunkelmanna C and Stephana P 2011 CFD simulation of boiling flows using the volume-of-fluid method within OpenFOAM. Numerical Heat Transfer, Part A: Applications 56(8): 631-646

Kutateladze S S and Leont A I 1966 Some applications of the asymptotic theory of the turbulent boundary layer. In: Proc. of Third Internat. Heat Transfer Conf., vol. 3, American Institute of Chemical Engineers, New York, pp. 1-6

Lahey R 2007 On the Computation of Multiphase Flows, The 12th International Topical Meeting on Nuclear Reactor Thermal Hydraulics (NURETH-12) Sheraton Station Square, Pittsburgh, Pennsylvania, U.S.A. September 30-October 4, 2007

Lakshminarasimhan M S, Hollingsworth D K and Witte L C 2000 Boiling incipience in narrow channels, HTD-Vol. 366-4, Proc. of ASME Heat Transfer Division, Volume 4, ASME IMECE 2000, pp. 55-63

Lazarek G M and Black S H 1982 Evaporative heat transfer, pressure drop and critical heat flux in a small diameter vertical tube with R-113. Int. J. Heat Mass Transfer 25(7): 945-960

Lee C H and Mudawar I 1988 A mechanistic critical heat flux model for subcooled flow boiling based on local bulk flow conditions. Int. J. Multiphase Flow 14: 711-728

Lee H J and Lee S Y 2001 Heat transfer correlation for boiling flows in small rectangular horizontal channels with low aspect ratios. Int. J. Multiphase Flow 27: 2043-2062

Lee M, Wong Y Y, Wong M and Zohar Y 2003 Size and shape effects on two-phase flow patterns in microchannel forced convection boiling. J. Micromech. Microeng. 13: 155-164

Lin S, Kew P A and Cornwell K 1999 Characteristics of air/water flow in small tubes. Heat Technol. 17(2): 63-70

Lin S, Kew P A and Cornwell K 2001 Two-phase heat transfer to a refrigerant in a $1 \mathrm{~mm}$ diameter tube. Int. J. Refrig. 24: 51-56

Liu S, Li J and Chen Q 2007 Visualization in flow pattern in thermosyphon by ECT. Flow Measurement Instrum. 18: 216-222

Liu Z and Winterton R H S 1991 A general correlation for saturated and subcooled flow boiling in tube and annuli. Int. J. Heat Mass Transfer 34: 2759-2766

Lockhart R W and Martinelli R C 1949 Proposed correlation of data for isothermal two-phase twocomponent flow in pipes. Chem. Eng. Prog. 45(1): 39-48

Lu Q, Suryanarayana N V and Christodoulu C 1993 Film thickness measurement with ultrasonic transducer. Exp. Thermal Fluid Sci. 7: 354-361

Mandhane J M, Gregory G A and Aziz K 1974 A flow pattern map for gas-liquid flow in horizontal pipes. Chem. Eng. Prog. 45: 39-48

Maqbool M H, Palm B and Khodabandeh R 2012 Experimental investigation of dryout of propane in uniformly heated single vertical mini-channels. Exp. Thermal Fluid Sci. 37: 121-129 
Mehendale S S, Jacobi A M and Shan R K 2000 Fluid flow and heat transfer at micro- and meso-scales with application to heat exchanger design. Appl. Mech. Rev. 53(7): 175-193

Mishima K and Hibiki T 1996 Some characteristics of air-water two-phase flows in small diameter tubes. Int. J. Multiphase Flow 22: 703-712

Mukherjee A and Kandlikar S G 2005 Numerical simulation of growth of a vapor bubble during flow boiling of water in a microchannel. Microfluidics Nanofluidics 1: 137-145

Ong C L and Thome J R 2010 Macro-to-microchannel transition in two-phase flow: Part 1 - Two-phase flow patterns and film thickness measurements. Exp. Thermal Fluid Sci. 35(1): 37-47

Ould Didi M B, Kattan N and Thome J R 2002 Prediction of two-phase pressure gradients of refrigerants in horizontal tubes. Int. J. Refrig. 25: 935-947

Oya T 1971 Upward liquid flow in small tube into which air streams (1st report, Experimental apparatus and flow patterns), vol. 14, no. 78, pp. 1320-1329

Pederson P C, Cakareski Z and Hermanson J C 2000 Ultrasonic monitoring for film condensation for applications in reduced gravity. Ultrasonics 38: 486-490

Peles Y P and Haber S 2000 A steady, one dimensional model for boiling two-phase flow in triangular microchannel. Int. J. Multiphase Flow 26: 1095-1115

Qi S L, Zhang P, Wang R Z and Xu L X 2007 Flow modeling of liquid nitrogen in micro tubes Part-II Heat transfer characteristics and critical heat flux. Int. J. of Heat and Mass Transfer. 50: 5017-5030

Revellin R and Thome J R 2007 Experimental investigation of R-134a and R-245fa two-phase flow in microchannels for different flow conditions. Int. J. Heat Fluid Flow 28(1): 63-71

Rouhani S Z and Axelsson E 1970 Calculation of void volume fraction in the sub cooled and quality boiling regions. Int. J. Heat Mass Transfer 13: 383-393

Saito Y, Mishima K, Tobito Y, Suzuki T and Matsubayshi M 2005 Measurements of liquid metal twophase flow by using neutron Radiography and electrical conductivity probe. Exp. Thermal Fluid Sci. 29: $323-330$

Schepper S C K, Heyndrickx G J and Marin G B 2008 CFD modelling of all gas-liquid and vapour-liquid flow regimes predicted by the Baker Chart. Chem. Eng. J. 138: 349-357

Schubring D, Ashwood A C, Shedd T A and Hulburt E T 2010 Planar laser induced fluoresence (PLIF) measurements of liquid flim thickness in annular flow Part I: Methods and data. Int. J. Multiphase Flow 36: $815-824$

Serizawa Z, Feng Z and Kawara K 2002 Two-phase flow in microchannels. Exp. Thermal Fluid Sci. 26: 703-714

Shah M M 1987 Improved general correlation for critical heat flux during upflow in uniformly heated vertical tubes. Int. J. Heat Fluid Flow 8(4): 326-335

Shah M M 1976 A new correlation for heat transfer during boiling through pipes. ASHRAE Trans. 82: 66-86

Shah R K 1986 Classification of heat exchangers. In: Kakac S, Bergles A E, Mayinger F. (Eds.), Heat Exchangers: Thermal Hydraulic Fundamentals and Design. Hemisphere Publishing Corp., Washington DC, pp. 9-46

Shiferaw D, Huo X, Karayiannis T G and Kenning D B R 2007 Examination of heat transfer correlations and a model for flow boiling of R134a in small diameter tubes. Int. J. Heat Mass Transfer 50: 5177-5193

Shiferaw D, Karayiannis T G and Kenning D B R 2009 Flow boiling in a $1.1 \mathrm{~mm}$ tube with R134a: Experimental results and comparison with model. Int. J. Therm. Sci. 48: 331-341

Son G and Dhir V K 1999 Dynamics and heat transfer associated with a single bubble during nucleate boiling on a horizontal surface. J. Heat Transfer-Transactions ASME 121: 623-631

Spedding P L and Chen J J J 1984 Holdup in two-phase flow. Int. J. Multiphase Flow 10: 307-339

Stahl P and Rohr P R 2004 On the accuracy of void fraction measurement by single beam GammaDensitometry for gas-liquid two phase flow in pipes. Exp. Thermal Fluid Sci. 28: 533-544

Steiner D and Taborek J 1992 Flow boiling heat transfer in vertical tubes correlated by an asymptotic model. Heat Transfer Eng. 13(2): 43-69

Sussman M and Smereka P 1994 A level set approach for computing solutions to incompressible two-phase flow. J. Comput. Phys. 114: 146-159 
Sussman M, Smereka P and Osher S 1994 A level set approach for computing solutions to incompressible two-phase flow. J. Comput. Phys. 114: 146-159

Tadrist L 2007 Review on the two phase flow instabilities in narrow spaces. Int. J. Heat Fluid Flow. 28: $54-62$

Taha T and Cui Z F 2006 CFD modelling of slug flow in vertical tubes. Chem. Eng. Sci. 61: 676-687

Taitel Y 1990 Flow pattern transition in two phase flow, Keynote lecture, In: 9th Internat. Heat Transfer Conf., Jerusalem, Israel, 19-24 August 1990, pp. 237-254

Taitel Y, Barnea D and Dukler A E 1980 Modelling flow pattern transition for gas-liquid transitions for steady upward gas-liquid flow in vertical tubes. AIChE J. 26(3): 345-354

Taitel Y and Dukler A E 1976 A model for predicting flow regime transitions in horizontal and near horizontal gas-liquid flow. AIChE J. 22: 47-55

Thome J R 1996 Boiling of new refrigerants: a state of the art review. Int. J. Refrigeration 19: 435-457

Tibiriçá C B, Nascimento F J and Ribatski G 2010 Film thickness measurement techniques applied to micro-scale two-phase flow systems. Exp. Thermal Fluid Sci. 34: 463-473

Tibiriçá C B and Ribatski G 2009 Flow boiling heat transfer of R134a and R245fa in a $2.3 \mathrm{~mm}$ tube. Int. J. Heat Mass Transfer 53(11-12): 2459-2468

Tong L S 1968 Boundary-layer analysis of the flow boiling crisis. Int. J. Heat Mass Transfer 11: $1208-1211$

Tong W, Bergles A E and Jensen M K 1997 Pressure drop with highly subcooled flow boiling in smalldiameter tubes, Exp. Thermal Fluid Sci. 1997, Elsevier Science Inc., Vol. 15, pp. 202-212

Tran T N, Wambsganss M W and France D M 1996 Small circular- and rectangular-channel boiling with two refrigerants. Int. J. Multiphase Flow 22(3): 485-498

Triplett K A, Ghiaasiaan S M, Abdei-Khalik S I and Sadowski D L 1999 Gas-liquid two phase flow in micro-channels, Part 1: two phase flow patterns. Int. J. Multiphase Flow 25: 377-394

Ursenbacher T, Wojtan L and Thome J 2004 Interfacial measurements in stratified types of flow. Part 1: New optical measurement technique and dry angle measurements. Int. J. Multiphase Flow 30: $107-124$

Venkatesan M, Sarit K Das and Balakrishnan A R 2010 Effect of tube diameter on two-phase flow patterns in mini tubes. Can. J. Chem. Eng. 88

Vijayarangan B R, Jayanti S and Balakrishnan A R 2006 Studies on critical heat flux in flow boiling at near critical pressures. Int. J. Heat Mass Transfer 49: 259-268

Warrier G R, Pan T and Dhir V K 2001 Heat transfer and pressure drop in narrow rectangular channels, Proc. of Fourth Internat. Conf. on Multiphase Flow, ASME, New Orleans, May 27-June 1, 2001

Weisman J and Pei B S 1983 Prediction of critical heat flux in flow boiling at low qualities. Int. J. Heat Mass Transfer 26: 1463-1477

Whalley P B 1980 Multiphase Flow and Pressure Drop. See Hewitt GF 1983 Heat Exchanger Design Handbook, vol. 2. Hemisphere, Washington DC, pp. 2.3.3-2.3.11

Wojtan L, Revellin R and Thome J R 2006 Investigation of saturated critical heat flux in a single, uniformly heated microchannel. Exp. Thermal Fluid Sci. 30: 765-774

Wojtan L, Ursenbacher T and Thome J R 2005 Development of a new heat transfer model for stratifiedwavy, dryout and mist flow regimes. Int. J. Heat Mass Transfer 48: 2970-2985

Woldesemayat M A 2006 Comparison of void fraction correlations for two-phase flow in horizontal and upward inclined flows. MS Thesis, Oklahoma State University, Stillwater, OK, Mechanical \& Aerospace Engineering

Wongwises S, Disawas S, Kaewon J and Onurai C 2000a Two-phase evaporative heat transfer coefficients of refrigerant HFC-134a under forced flow conditions in a small horizontal tube. Int. Commun. Heat Mass Transfer 27: 35-48

Xu J L, Wong T N and Huang X Y 2006 Two-fluid modelling for low-pressure subcooled flow boiling. Int. J. Heat Mass Transfer 49: 377-386

Yan Y Y and Zu Y Q 2007 A lattice Boltzmann method for incompressible two-phase flows on partial wetting surface with large density ratio. J. Comput. Phys. 227: 763-775 
Yan Y Y and Zu Y Q 2008 Numerical modelling based on lattice Boltzmann method of the behaviour of bubbles flow and coalescence in microchannels, In: Proc. of 6th Internat. Conf. on Nanochannels, Micro-channels, and Minichannels, ICNMM2008 (PART A), pp. 313-319

Yeoh G H, Sherman C, Cheung P, Tu J Y and Mark K M 2008 Fundamental consideration of wall heat partition of vertical subcooled boiling flows. Int. J. Heat Mass Transfer 51: 3840-3853

Yu S C M, Tso C P and Liew R 1996 Analysis of thin film thickness determination in two-phase flow using multifibre optical sensor. Appl. Math. Model. 20: 540-548

Yu W, France D M and Wambasgans S 2002 Two phase pressure drop boiling heat transfer and critical heat flux to water in a small diameter tube. Int. J. Multiphase Flow. 28: 927-941

Zhang W, Hibiki T and Mishima K 2004 Correlation for flow boiling heat transfer in mini- channels. Int. J. Heat Mass Transfer 47: 5749-5763

Zhang W, Hibiki T and Mishima K 2010 Correlations of two-phase frictional pressure drop and void fraction in mini-channel. Int. J. Heat Mass Transfer 53: 453-465

Zhang W, Hibiki T, Mishima K and Mi Y 2006 Correlation of critical heat flux for flow boiling of water in mini-channels. Int. J. Heat Mass Transfer 49: 1058-1072

Zhao J F 2000 On the void fraction matched model for the slug to annular transition at microgravity. $J$. Basic Sci. Eng. 8(4): 394-397

Zhao T S and Bi Q C 2001 Pressure drop characteristics of gas-liquid two-phase flow in vertical miniature triangular channels. Int. J. Heat Mass Transfer 44: 2523-2534

Zhao Y, Molki M, Ohadi S V and Dessiatoun S V 2000 Flow boiling of $\mathrm{CO}_{2}$ in a microchannel. ASHRAE Trans. 106(1): 437-445

Zhihu H, Yanhu Y and Zhou F L 2006 Local flow regime transition criteria of gas-liquid two-phase flow in vertical upward tube with a horizontal rod. Chinese J. Chem. Eng. 14(4): 442-449

Zu Y Q and Yan Y Y 2009 A numerical investigation of electro-hydrodynamic (EHD) effects on bubble deformation under pseudo-nucleate boiling conditions. Int. J. Heat Fluid Flow 30: 761-767 